\title{
Four Types of LME Cracks in RSW of Zn-Coated AHSS
}

\section{The thermal-mechanical-metallurgical characteristics of various crack locations are evaluated, and a classification of LME cracks is proposed}

\author{
BY S. P. MURUGAN, V. VIJAYAN, C. J, AND Y.-D. PARK
}

\begin{abstract}
Zinc-coated advanced high-strength steels are known to be susceptible to liquid metal embrittlement (LME) cracking during resistance spot welding (RSW). Despite numerous reports with regard to LME during RSW, a systematic approach has not been proposed for the classification of cracks based on the cracking mechanism. The objective of this study was to characterize the LME cracks at various RSW locations, and thereby propose a classification method to identify the mechanism of the LME cracks at each location. The experimental results revealed the LME cracks were concentrated at certain weld locations and exhibited different features in terms of length, number, and orientation, owing to the synergetic effect of temperature, stress, microstructure, time of exposure to liquid zinc, and time of exposure to tensile stress at the corresponding locations. Thus, the LME cracks were classified into four categories, namely type $A$, type $B$, type $C$, and type $D$, based on the formation location. The effect of time of exposure to liquid zinc and tensile stress on LME cracking revealed the time dependency of LME in RSW. The nature of contact between the electrode and the sheet, and the heat input during welding, were found to be the main reasons for the difference in the thermal, mechanical, and metallurgical characteristics of various crack locations, which caused the formation of various LME crack types.
\end{abstract}

\section{KEYWORDS}

- Liquid Metal Embrittlement $\bullet$ Resistance Spot Welding

- Advanced High-Strength Steel • Zinc-Coated Steels

- Crack • Stress Development

\section{Introduction}

In the automotive industry, zinc coating is used as an effective technique to prevent advanced high-strength steels (AHSS) from corrosion (Ref. 1). Generally, automotive steels are available in two types of zinc coatings, namely galvanized and galvannealed. Galvanized steels are produced by hot dipping into a molten zinc bath and subsequent formation of uniform coating, whereas galvannealed steels are produced by a post-hot-dip heat treatment at $450^{\circ}$ to $590^{\circ} \mathrm{C}$ for a duration of approximately $10 \mathrm{~s}$. This process enables the diffusion of substrate iron into the coating and forms thin layers of Fe-Zn intermetallic compounds (Refs. 1, 2). Despite corrosion protection, zinc coatings on steel are prone to liquid metal embrittlement (LME) during hightemperature manufacturing processes such as hot press forming, hot-dip galvanizing, and resistance spot welding (RSW) (Refs. 3-6). Zinc-assisted LME is the penetration of liquid zinc into the steel matrix through grain boundaries of a susceptible microstructure aided by tensile stress, causing grain boundary decohesion and cracking in the steel.

Process temperatures higher than the melting point of $\mathrm{Zn}$ $\left(420^{\circ} \mathrm{C}\right)$ causes the galvanized coating to melt and serve the necessary condition of liquid metal availability.

Resistance spot welding is a fusion welding process used to join steel sheets in automobile production lines in which the heat required for melting is produced by passing a high current through small spots using copper electrodes (Refs. 7-10). In RSW, LME cracks can significantly deteriorate the spot weldability of Zn-coated AHSS (Refs. 11-16). The zinc coating in steels melts at a relatively lower temperature $\left(420^{\circ} \mathrm{C}\right)$ to produce liquid zinc at the sheet surface during RSW. The melting of zinc along with the presence of high tensile stress generated during the thermomechanical welding cycle lead to the penetration of liquid zinc into the steel matrix, causing LME (Refs. 13, 17, 18). As the LME crack can affect the mechanical performances of the spot welds, these cracks need to be eliminated.

Most of the existing literature on Zn-LME is concerned with ductility loss and crack propagation with a hightemperature tensile test (HTTT) (Refs. 4, 19, 20). Liquid metal embrittlement cracking can be studied using HTTT; however, the presence of water-cooled copper electrodes makes LME in RSW unique. The copper electrodes are found to influence LME cracking in several ways, mainly by the formation of brittle $\mathrm{Cu}-\mathrm{Zn}$ intermetallic compound due to the reaction between liquid zinc from the coating and copper from the electrode (Refs. 11, 21). Furthermore, the geometry of the electrode also influences LME due to the variation in temperature, stress, and availability of zinc by manifesting different contact conditions (Refs. 21-24). Con- 

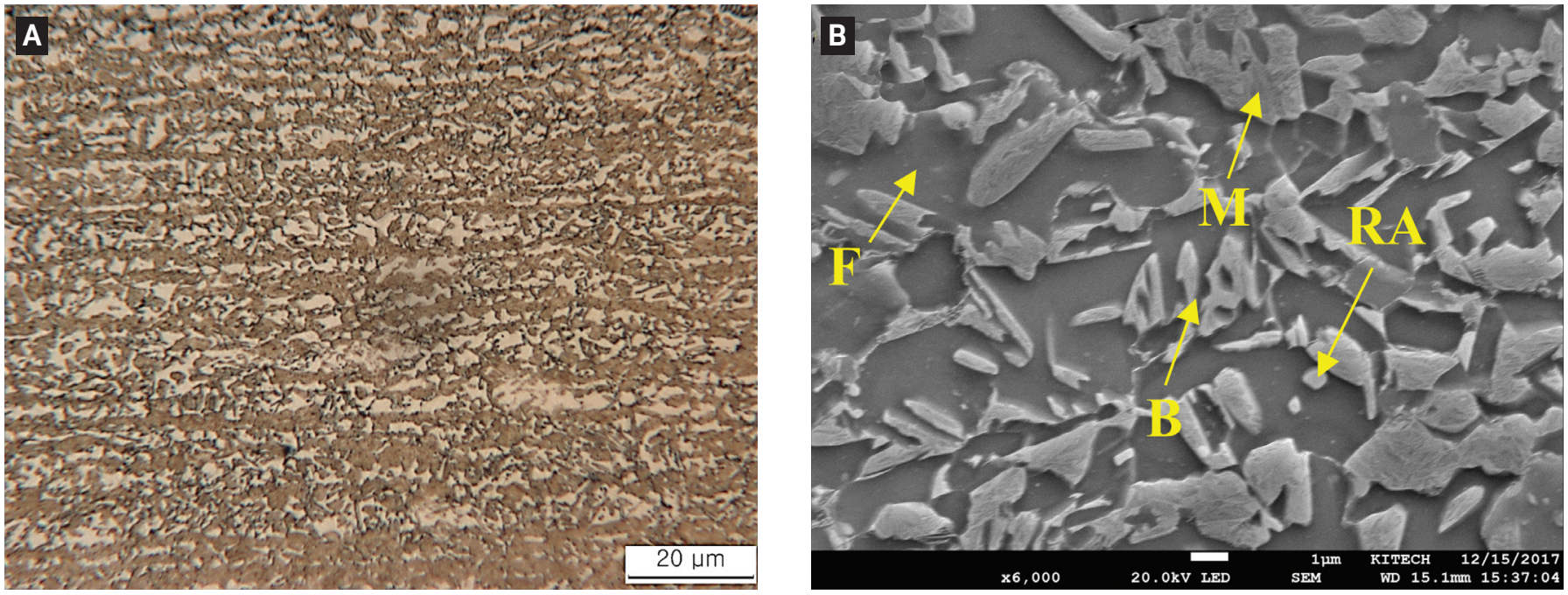

Fig. 1-Microstructure of the base metal: A - Optical image; B - SEM image (F: ferrite; RA: retained austenite; B: bainite; M: martensite).

sequently, it is important to consider the presence of the electrode and the electrode-to-sheet $(\mathrm{E} / \mathrm{S})$ interface during the study of LME.

Moreover, a review of the available literature suggests LME cracks are concentrated at specific locations of the welds. Hence, various classifications of the cracks were proposed based on the crack location; however, these classifications differed in many ways (Refs. 11, 18, 23, 25). Choi et al. (Ref. 18) outlined three types of cracks in RSW, whereas Bhattacharya (Ref. 23) showed four types. On the other hand, the industrial standard of the American Welding Society proposed a grouping of surface cracks, but not LME, based on the location (Ref. 25). Instead of considering the reason for crack formation, the impact of surface cracks on the mechanical properties of the spot welds were considered as the criterion for the grouping. Additionally, the cracks formed at the sheet-to-sheet (S/S) interface were not discussed in these reports. The classification of LME cracks based on the location is important for carrying out further investigations on 1) the mechanism of LME cracking, and 2) the performance of the welds. From the basics of RSW, each crack location is expected to experience different thermal and mechanical characteristics due to the difference in the heating and cooling rates, temperature gradient, contact pressure, etc. (Ref. 26).

Subsequently, the study of the different types of LME cracks will provide information toward formulating the mechanism of LME during RSW. From the point of view of weld performance, the impact of LME cracks at various locations on the joint integrity is expected to be different. The cracks formed at the center of the weld surface would be less influential because it is away from the edge of the nugget. On the other hand, the cracks at the edge of the E/S or S/S interface would have detrimental effects because they are located near the edge of the nugget. Therefore, the safety standards for the cracks permissible or allowable crack length for various cracks can be different. Hence, the steelmakers and automotive manufacturers will be interested to have a classification of LME cracks to make appropriate acceptance standards.
This paper investigates the formation of LME cracks at various locations in RSW and proposes a systematic classification of LME cracks. An attempt is made to understand the formation mechanism of LME cracks at various locations through a detailed characterization of the crack locations using experimental and simulation techniques. Specifically, the features of various LME cracks are correlated with the combination of thermal, mechanical, and metallurgical characteristics of the corresponding crack locations. The new factors, namely "exposure times" to liquid zinc and tensile stress, believed to influence LME in RSW are introduced here to explain the time dependency of LME cracking.

\section{Experimental Procedure}

\section{Materials}

The behavior of LME cracking in zinc-coated advanced high-strength steels was studied using a 1.2-mm-thick galvannealed (GA) complex phase (CP) steel with a chemical composition of $0.2 \mathrm{wt}-\%$ C, $2.2 \mathrm{wt}-\% \mathrm{Mn}$, and $1.0 \mathrm{wt}-\% \mathrm{Si}$ as well as mechanical properties of $970 \mathrm{MPa}$ ultimate tensile strength, $370 \mathrm{MPa}$ yield strength, and $16 \%$ elongation. Complex phase steel is developed for automobile parts that require higher flangeability and yield strength/tensile strength ratio, and it contains a mixture of ferrite, bainite, martensite, retained austenite, and precipitates (Ref. 27). The microstructure of the steel shown in Fig. 1 consists of ferrite, martensite, bainite, and retained austenite.

\section{Resistance Spot Welding}

The resistance spot welding of the samples was carried out using a servo $C$-type welding gun with a medium frequency direct current power source. A dome-shaped $\mathrm{Cu}-\mathrm{Cr}$ electrode with a body diameter of $16 \mathrm{~mm}$, face diameter of 6 $\mathrm{mm}$, and face radius curvature of $50 \mathrm{~mm}$ was used for experiments. The welding parameters for the study were chosen based on the ISO 18278-2:2004 standard and are shown in 

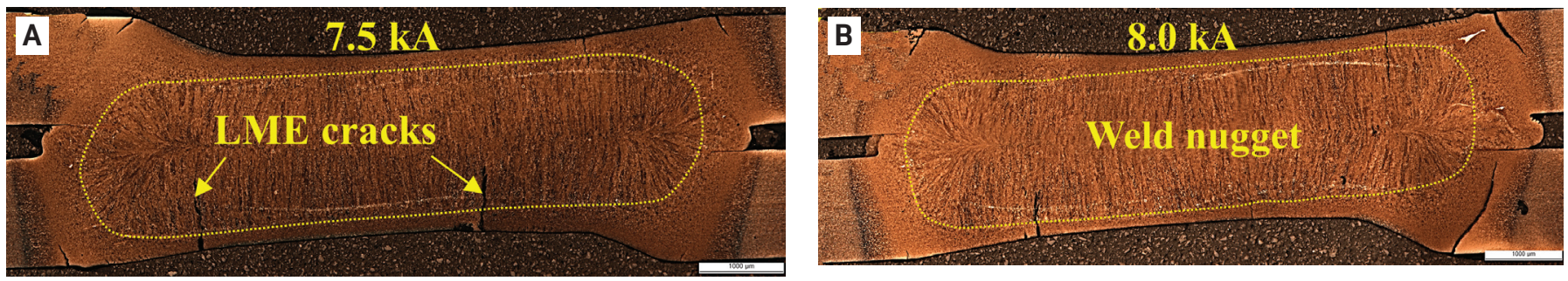

\section{C}
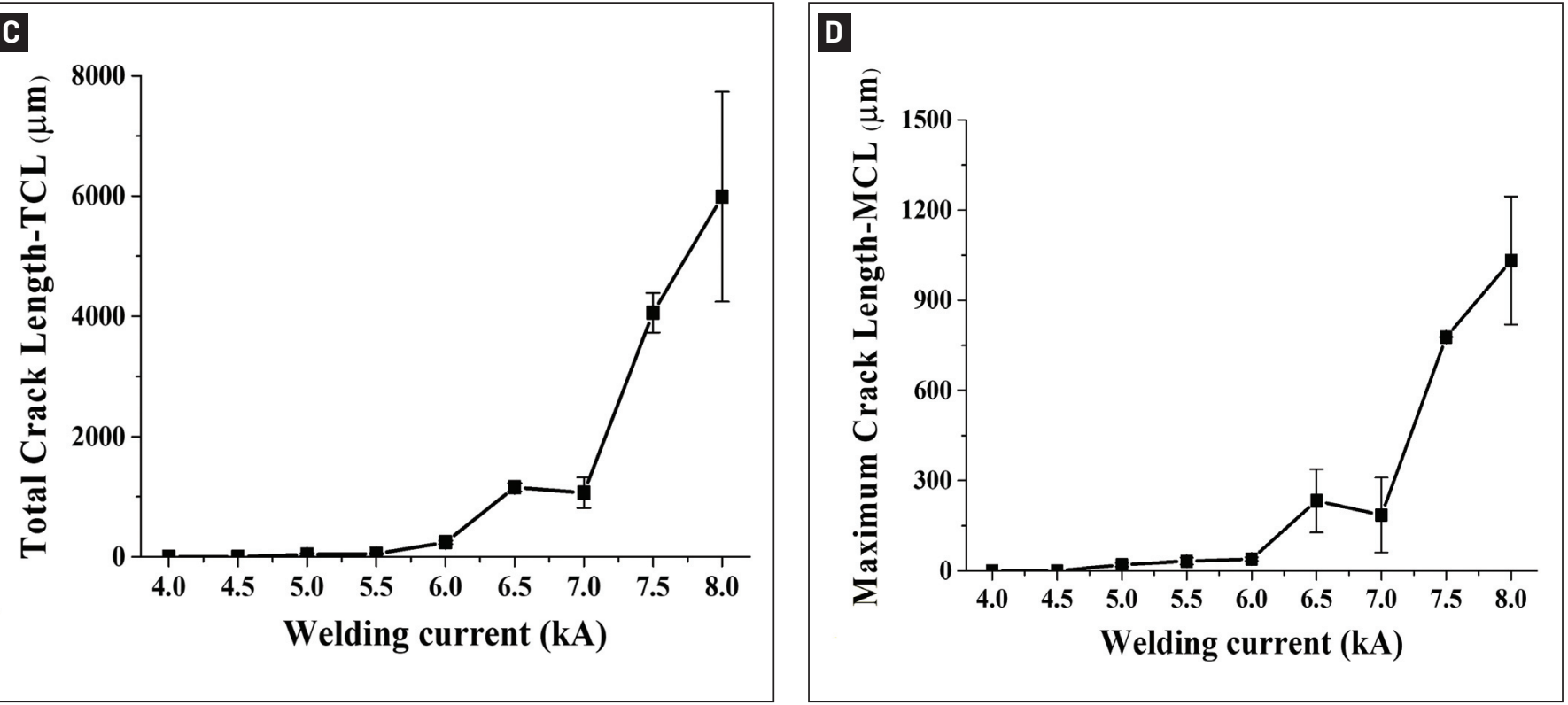

E
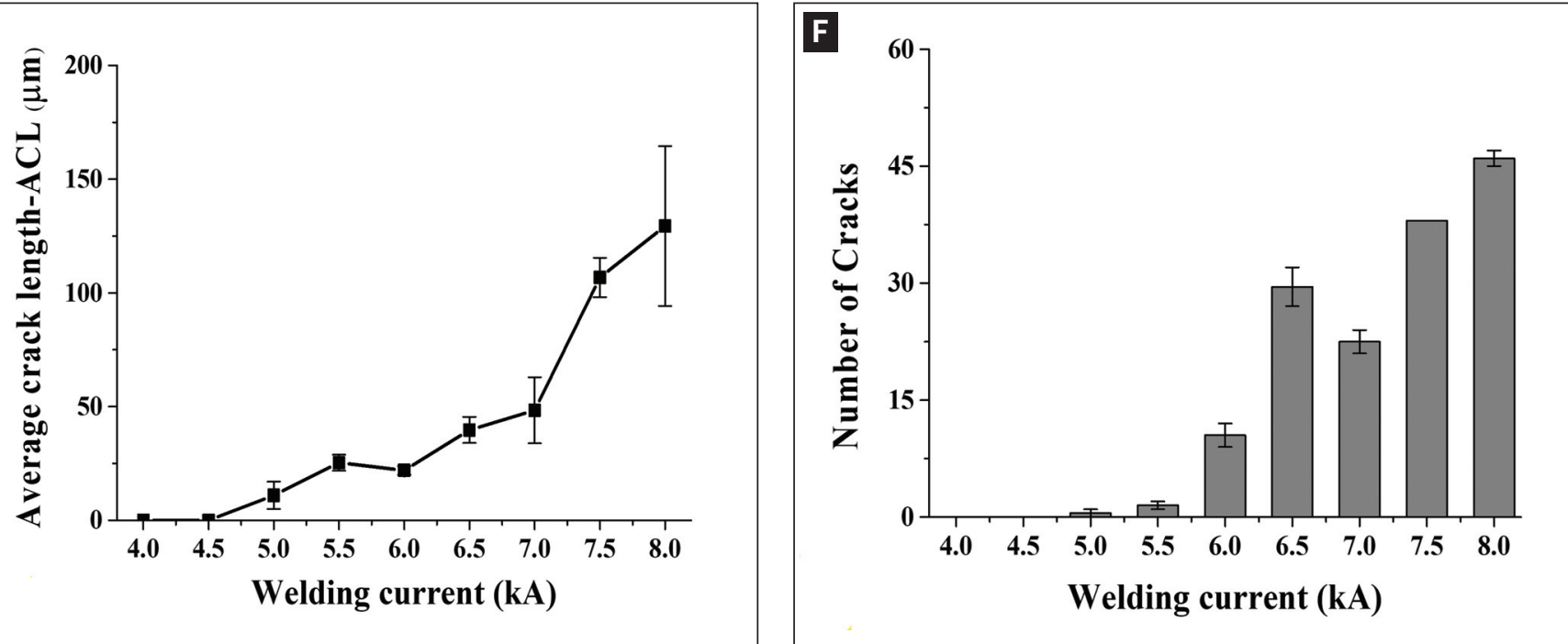

Fig. 2 - Cross-sectional image of the weld with welding current: $A-7.5 \mathrm{kA} ; \mathrm{B}-8.0 \mathrm{kA}$. Variation of LME cracking with welding current: C - TCL; D - MCL; E - ACL; F - number of cracks.

Table 1. In Table 1, the squeeze time is the time interval between the application of electrode force and the application of welding current; the weld time is the time period during which the welding current is applied to the material through the electrode; and the hold time is the time during which the electrode force is provided to the weld after the welding current ends (Ref. 28). The welding current was varied with an intention to produce welds with different heat inputs.

\section{Metallographic Studies}

A high-magnification, high-resolution optical microscope (Olympus BX51M) was used to obtain the images of the cracks from the cross sections of the resistance spot welds. Individual crack lengths were measured for each sample and presented in terms of the total crack length (TCL), the maximum crack length (MCL), and the average crack length $(\mathrm{ACL})$. Maximum crack length is used frequently to explain 


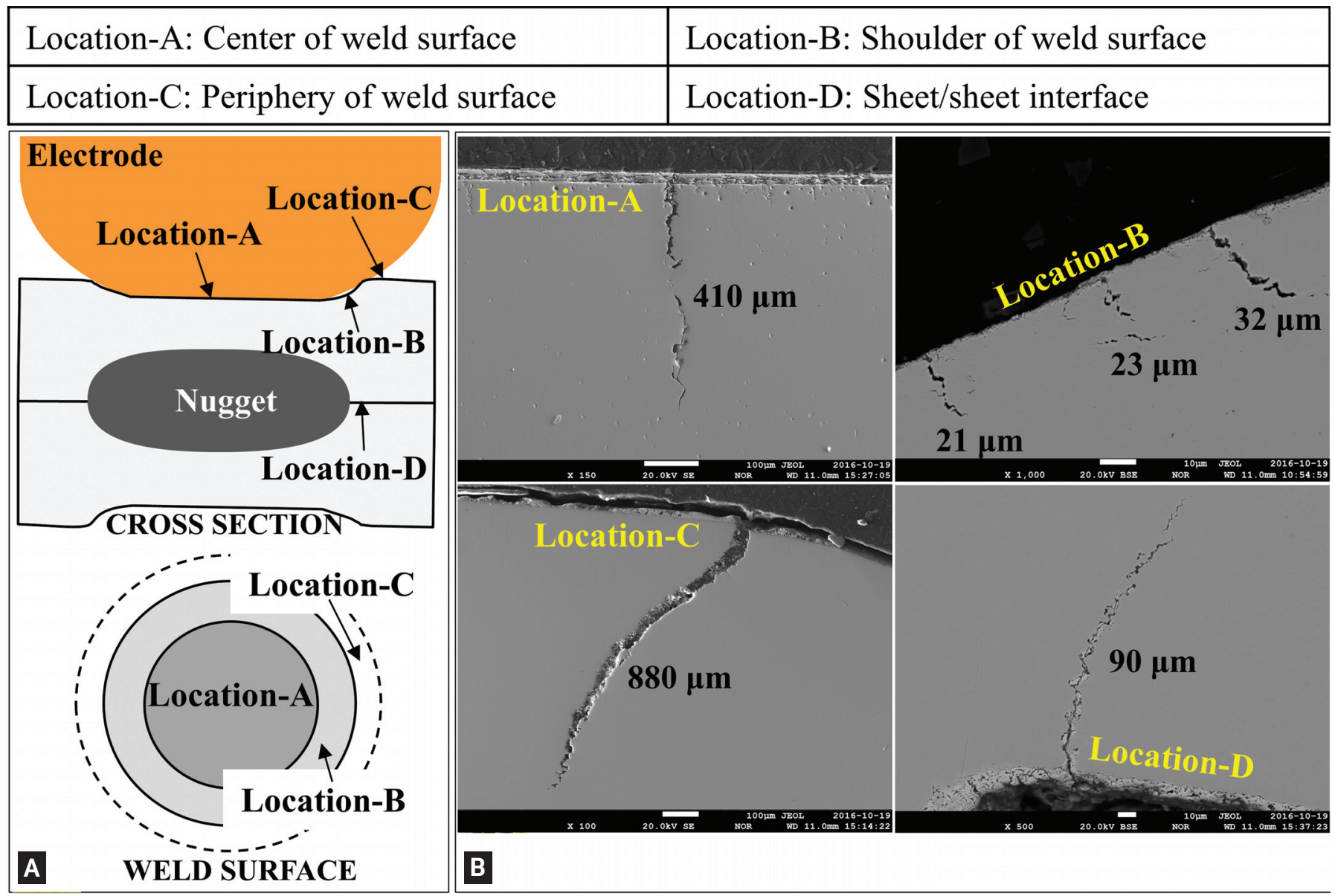

Fig. $3-A-$ Schematic diagram of the preferred locations of crack formation; B - SEM images of cracks at various locations.

the LME cracking behavior because it provides a direct measure of the length of the embrittled area from the surface (Ref. 29). The number of cracks and crack orientation (angle) were also determined to explain characteristics of the cracks. Crack orientation was measured as the acute angle between the plane of crack propagation and the plane containing the sheet surface. Microstructural evaluations were carried out using optical and field emission scanning electron microscopes (FE-SEM; JEOL JSM-7200F) after chemical etching with $3 \%$ nital solution. The phase fractions of ferrite in the base metal and the various crack locations in the weld were measured from the SEM images using the ImageJ software. Thresholding was first performed on the images using the ImageJ software to differentiate the ferrite from the other phases, such as bainite and martensite. Thresholding is a technique of segmentation of an image into two or more classes of pixels. Then, the area of the segmented ferrite was measured using a tool in ImageJ called Analyze Particles. An electron probe microanalyzer (FE-
EPMA; JEOL JXA-8530F) was used for the elemental analysis of various LME cracks.

\section{Simulation}

To understand and determine the temperature history and stress distribution during RSW, a commercial software called SORPAS ${ }^{\circledR}$ was used. The same welding parameters were provided as in the experimental procedure. Thermo-Calc ${ }^{\circledR \mathrm{TM}}, \mathrm{a}$ software package for the calculation of thermodynamic and phase equilibria, was used to simulate the equilibrium phase fraction of the given steel at different temperatures.

\section{Results}

\section{LME Cracks in GA-CP Steels}

Figure 2A and B shows the cross-sectional images of spot

Table 1 - Welding Conditions Used to Make Resistance Spot Welds in This Study

Electrode Force (kN)
Weld Time (s)

300

Hold Time (ms)

300
Water Flow Rate (L/min) 


\begin{tabular}{|c|c|c|c|c|c|c|c|c|c|}
\hline Welding Current $(\mathrm{kA})$ & 4.0 & 4.5 & 5.0 & 5.5 & 6.0 & 6.5 & 7.0 & 7.5 & 8.0 \\
\hline Location-A & $\mathbf{X}$ & $\mathbf{X}$ & $\mathbf{X}$ & $\mathbf{O}$ & $\mathbf{O}$ & $\mathbf{O}$ & $\mathbf{O}$ & $\mathbf{O}$ & $\mathbf{O}$ \\
\hline Location-B & $\mathbf{X}$ & $\mathbf{X}$ & $\mathbf{O}$ & $\mathbf{O}$ & $\mathbf{O}$ & $\mathbf{O}$ & $\mathbf{O}$ & $\mathbf{O}$ & $\mathbf{O}$ \\
\hline Location-C & $\mathbf{X}$ & $\mathbf{X}$ & $\mathbf{X}$ & $\mathbf{X}$ & $\mathbf{X}$ & $\mathbf{O}$ & $\mathbf{O}$ & $\mathbf{O}$ & $\mathbf{O}$ \\
\hline Location-D & $\mathbf{X}$ & $\mathbf{X}$ & $\mathbf{X}$ & $\mathbf{X}$ & $\mathbf{X}$ & $\mathbf{X}$ & $\mathbf{X}$ & $\mathbf{O}$ & $\mathbf{O}$ \\
\hline $\mathbf{A}$ & \multicolumn{8}{|c|}{ X- No cracking O- Cracking } \\
\hline
\end{tabular}
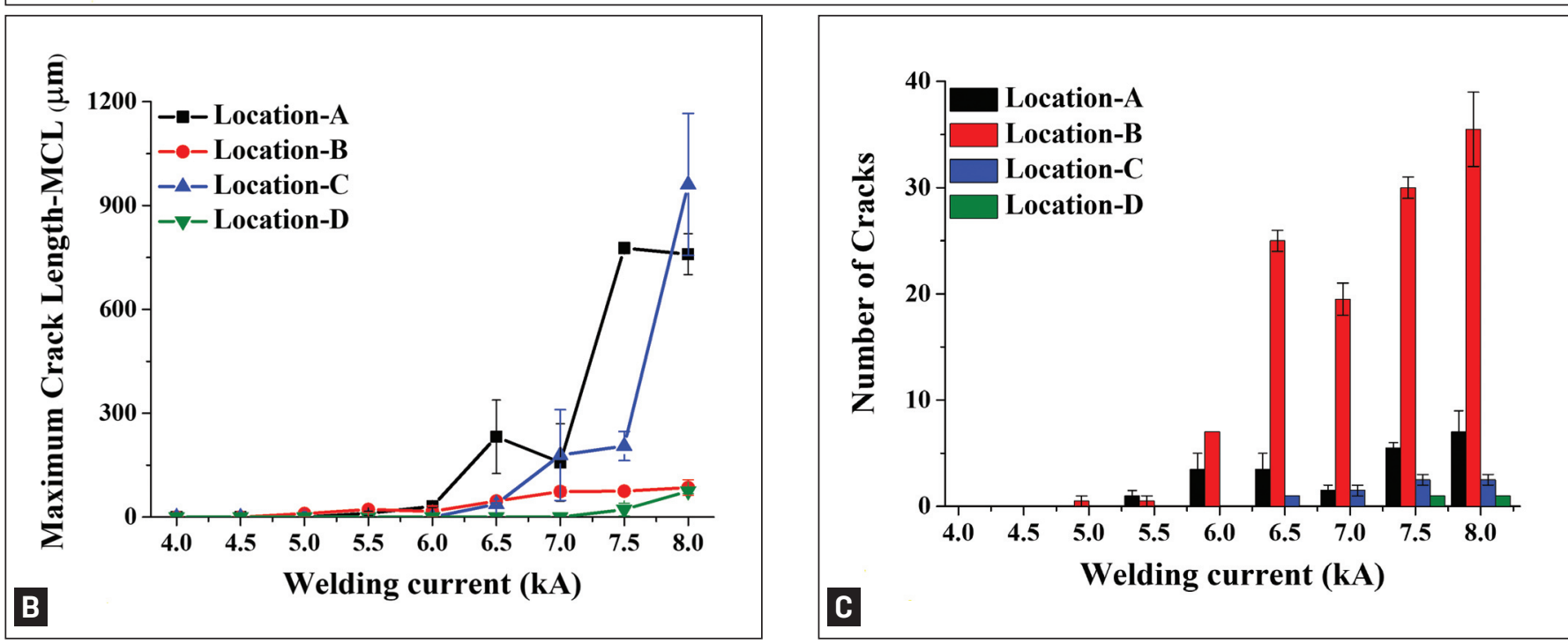

Fig. 4-A - Formation of cracks at various locations with different welding currents ( $\mathrm{X}$ : no cracking; 0 : cracking); B - maximum crack length of LME cracks at various locations; $C$ - number of LME cracks at various locations.

welds with welding currents of 7.5 and $8.0 \mathrm{kA}$. Several cracks were observed at different regions of the spot welds, notably a large crack with a crack length of around $1000 \mu \mathrm{m}$ at $8.0 \mathrm{kA}$. A few cracks formed at the weld surface and entered the fusion zone (FZ), whereas a few others formed in the heat-affected zone (HAZ). Severity of the cracks, in terms of both number of cracks and crack length, increased with the welding current, especially above a current of 6.0 kA, as shown in Fig. 2.

\section{LME Cracks at Various Locations}

From Fig. 2, it is difficult to identify a single type of LME crack because the cracking pattern changed with the heat input. However, precise examinations of various samples revealed the relationship between the crack length, the number of cracks, and the crack location. For instance, the cracks in the center of the weld surface were deep, but they were few, whereas the cracks at the edge of the E/S interface with an inclined indentation contained a lot of small cracks. To explain the behavior of LME cracking based on the crack length, crack number, crack orientation, and crack location, further observations were made with different welds.

It was found that the LME cracks were mainly concen- trated at four locations, as seen in the cross section of the welds: at the center of the weld, shoulder of the weld, periphery of the weld, and S/S interface. The schematic diagram of the locations of crack formation and the SEM images of LME cracks at various locations are shown in Fig. 3, where the different locations are designated henceforth as A, B, C, and D. Location A corresponds to the area that was in direct contact with the near-flat surface of the domeshaped electrode. Location B was formed at the weld surface where the electrode surface did not initially make direct contact with the sheet; however, at a later stage of welding, the electrode surface touched the sheet and made a shoulderlike inclined surface. In previous reports, the cracks formed at this location were either excluded or considered along with the cracks formed at the peripheral region (Refs. 18, 23). However, this location exhibited a unique characteristic in terms of the length, number, and orientation of the cracks, and hence is considered as a separate group of cracks. Location $C$ is at the edge of the $\mathrm{E} / \mathrm{S}$ interface with no contact with the electrode surface during the entire welding process. Liquid metal embrittlement cracks were also formed at the $\mathrm{S} / \mathrm{S}$ interface (location $\mathrm{D}$ ) outside the edge of the nugget.

The formation of various LME cracks with different welding currents is shown in Fig. 4A. The crack formation at location B started at relatively lower welding currents, while the 


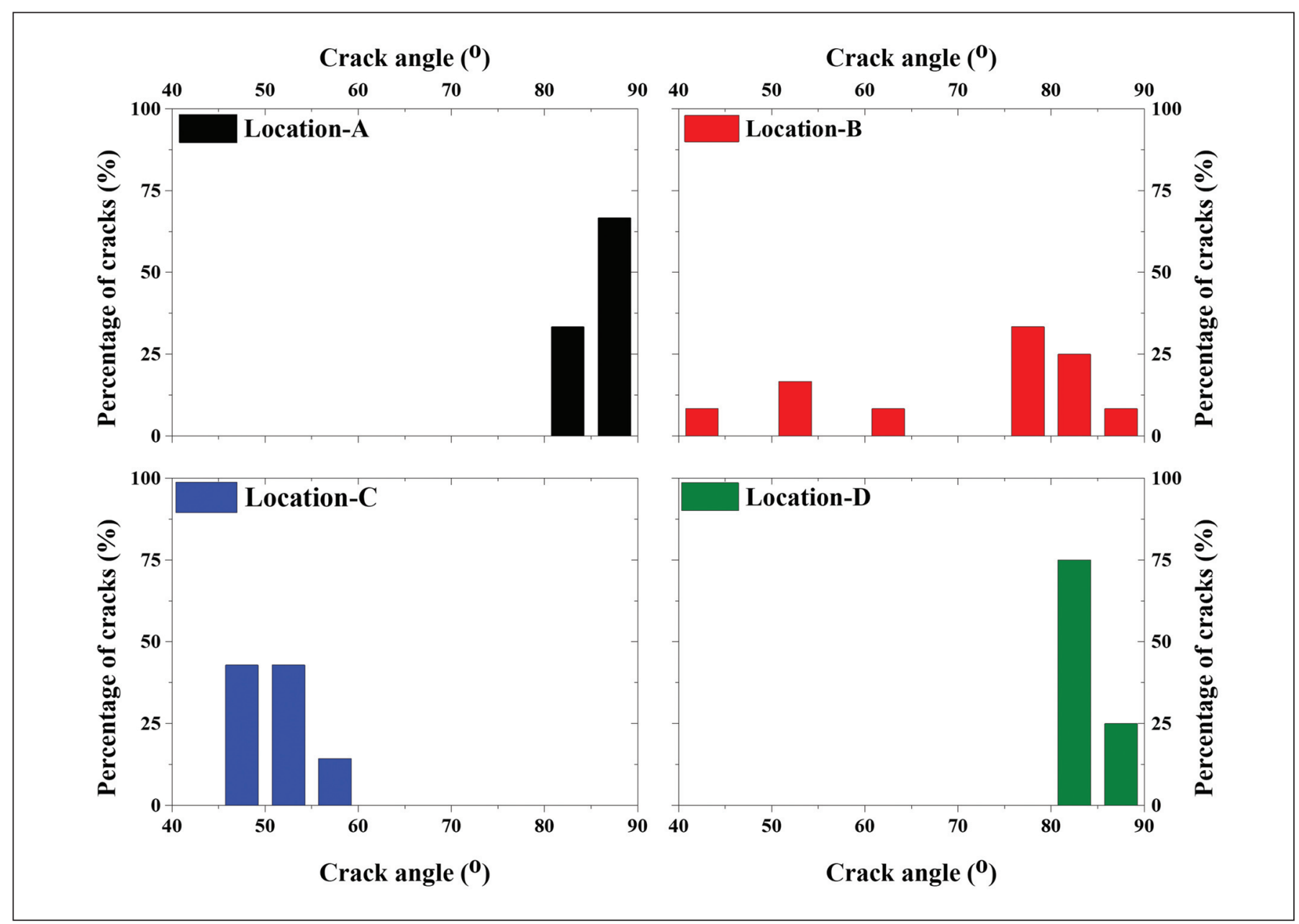

Fig. 5 - Orientation of LME cracks at various locations.

cracks at the other locations formed only at higher welding currents. The quantitative characterization of various cracks in terms of MCL and the number of cracks as functions of welding current are shown in Fig. 4B and C. Even though the crack length and the number of cracks increased with the welding current, significant differences were observed between the locations. Cracks at locations $\mathrm{A}$ and $\mathrm{C}$ displayed large crack lengths in the order of 300 to $1000 \mu \mathrm{m}$, whereas cracks at B and $\mathrm{D}$ always formed as small cracks with crack lengths ranging from a few micrometers to $100 \mu \mathrm{m}$. Numerous cracks were observed at location B and were formed as a series of cracks in the shoulder region of the electrode indentation. However, the number of cracks at other locations were relatively low.

The crack orientation, which is related to the temperaturestress field, was measured as the crack angle with respect to the crack initiating surface - Fig. 5. Cracks in all the welds with welding currents from 5.0 to $8.0 \mathrm{kA}$ were considered for the measurement of crack orientation. Substantial differences in the crack orientation were observed between the cracks formed at various locations. It was found that the cracks at locations A and D propagated nearly perpendicular to the surface with crack angles of 80 to $90 \mathrm{deg}$, and the cracks at $C$ propagated at angles of 45 to $60 \mathrm{deg}$. In contrast, the cracks at B did not exhibit any specific direction; they propagated at angles of 40 to $90 \mathrm{deg}$. The cracks at locations
C and D exhibited slight deviation from their original orientation upon deep propagation, especially in location $C$, where the crack orientation was changed to approximately $80 \mathrm{deg}$. This could be due to the change in the local temperature gradient, which determines the magnitude and direction of thermal stress (Ref. 30).

It is valuable to note that heat input is an important factor that affected the features of LME cracks at various locations. Cracks at A, C, and D were formed only at relatively higher heat inputs, whereas cracks at B formed at even low heat inputs. Furthermore, the length of the cracks at A and $C$ dramatically increased with heat input; however, the cracks at B and D did not show ample variation in length. The number of cracks at B significantly increased with the heat input. This shows the influence of heat input on the formation of cracks at various locations.

\section{Temperature and Stress Distribution at Various Locations}

As reported by previous researchers, LME cracks in RSW are formed because of thermal-mechanical conditions that prevail during RSW (Refs. 13, 17, 18). As a result, it is important to investigate the temperature and stress distribu- 


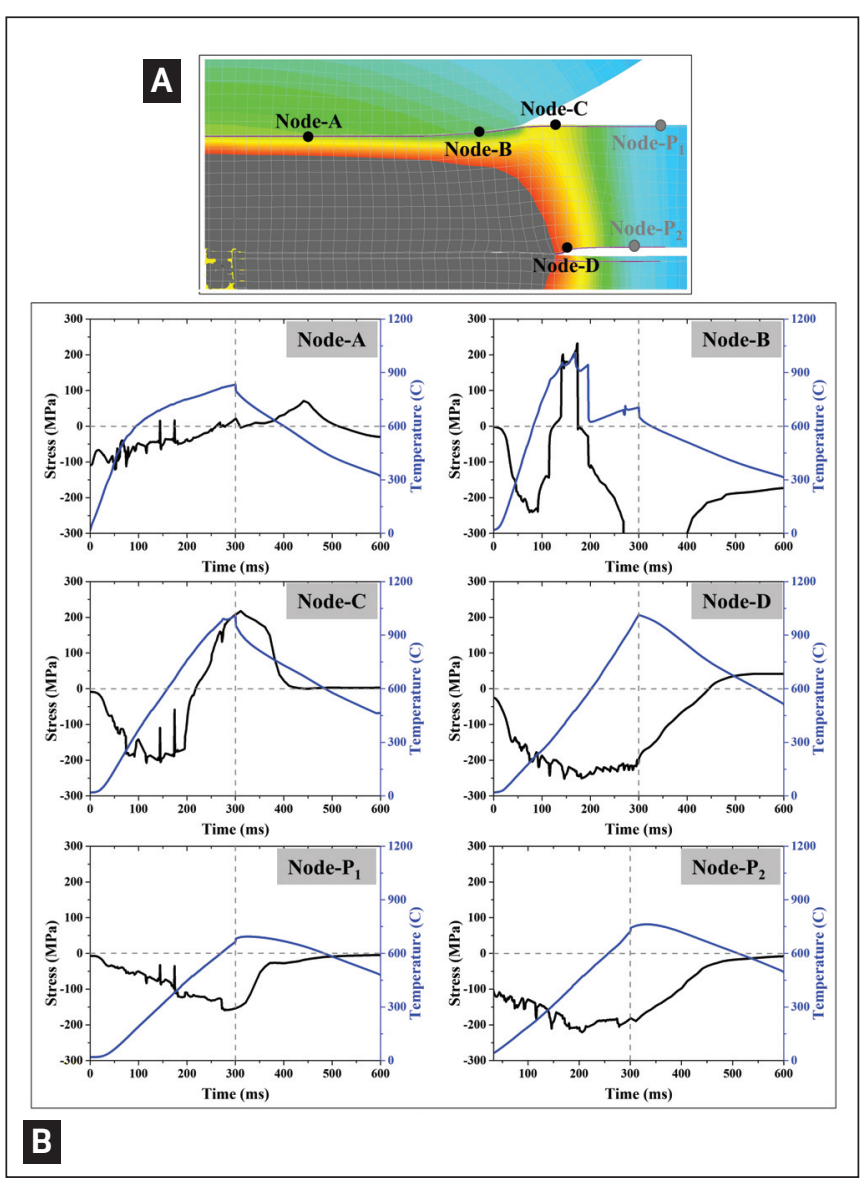

Fig. 6-A - Positioning of the nodes in various crack locations for the thermal-mechanical analysis; $B$ - temperature and stress distribution at various nodes obtained using SORPAS.

tion at different crack locations. Figure 6 shows the results of the thermal-mechanical analysis of the locations of various cracks performed using SORPAS for a spot weld with welding current of $8.0 \mathrm{kA}$. From each area, one node was selected to illustrate the temperature and stress distribution of the corresponding area, namely A, B, C, and D. In location A, LME cracks were normally observed at a distance of at least $1 \mathrm{~mm}$ away from the center of the weld. The elements within 1-mm distance from the center were not considered for the analysis. Two nodes were considered from the E/S interface $\left(\mathrm{P}_{1}\right)$ and the $\mathrm{S} / \mathrm{S}$ interface $\left(\mathrm{P}_{2}\right)$ for the comparison of thermal-mechanical characteristics of the noncracked locations.

The maximum temperature at location $\mathrm{A}$ reached up to $829^{\circ} \mathrm{C}$ at the end of the weld time $(300 \mathrm{~ms})$ with a heating rate of $2760^{\circ} \mathrm{C} / \mathrm{s}$. The temperature at this location was relatively low even though it was close to the FZ. Water-cooled electrodes conducted the heat away and kept the temperature low. During hold time, the temperature decreased rapidly as the current was turned off. During the weld time, the stress developed at the center was mainly compressive, while at the end of the weld time or during hold time it changed completely into tensile and reached a maximum value of $66 \mathrm{MPa}$. It is presumed that the LME crack formed in location A was initiated at the end of the weld time or the beginning of the hold time, and the major stages of the crack propagation occurred during the hold time.

Location B experienced a higher temperature rise than that of location A. The peak temperature and the stress at the shoulder area reached approximately $1040^{\circ} \mathrm{C}$ and 223 $\mathrm{MPa}$, respectively, as shown in Fig. 6, and suddenly dropped down to $570^{\circ} \mathrm{C}$ and $-100 \mathrm{MPa}$ (compression), when the electrode surface encountered the area at a weld time of about $180 \mathrm{~ms}$. Here, the average heating rate, up to the maximum temperature, was predicted to be $10,000^{\circ} \mathrm{C} / \mathrm{s}$.

Location $C$ experienced high temperature and tensile stress during welding. This area existed in the gap between the electrode and the steel sheet, so the inadequate contact between the water-cooled electrode and the steel sheet caused insufficient cooling, which interrupted the heat extraction from the sheet, eventually ending up with the accumulation of heat and temperature rise. The peak temperature and the peak stress at this area approached $1053^{\circ} \mathrm{C}$ and $290 \mathrm{MPa}$, respectively, with an average heating rate of $3500^{\circ} \mathrm{C} / \mathrm{s}$ up to the maximum temperature.

Location D experienced a peak temperature of $1185^{\circ} \mathrm{C}$ with a heating rate of $3800^{\circ} \mathrm{C} / \mathrm{s}$; however, the stresses generated in this area during the weld time and the beginning of the hold time were compressive in nature, as shown in Fig. 6. It existed at the S/S interface near the edge of the nugget (weld interface). In fact, a spectrum of temperature ranging from melting temperature to room temperature always existed outside the nugget with a lower temperature gradient. The temperature gradient was in the horizontal direction as the heat dissipation from this region was completely through the less-conductive base metal.

The results of temperature and stress distribution analysis at various locations are summarized in Fig. 7, in which the peak temperature and the peak stress at each element were plotted against the distance from the center of the weld (for locations A, B, and C) or the distance from the edge of the nugget (for location D). Location A exhibited relatively lower temperature and stress because it always remained in contact with the water-cooled electrode. On the other hand, locations $B$ and $C$ experienced high temperature and tensile stress owing to the formation of a gap between the electrode and the steel sheet and subsequent lack of cooling. On the contrary, location D exhibited high temperature but low tensile stress because it was close to the edge of the nugget and far away from the electrode. Thus, it can be summarized that the difference in temperature and stress distribution at each location was generated from the difference in the contact condition between the electrode and the sheet surface. The temperature and stress distribution at each location can further be influenced by the heat input (welding current). Higher heat input (welding current) can cause higher temperature and tensile stress at A, B, C, and D. In contrast, stress distribution at location $\mathrm{D}$ might be mainly influenced by several field variables, such as gap, electrode tilting, or fixtures (Ref. 31).

\section{Distribution of Zinc}

Electron probe micro-analysis (EPMA) was performed along the cracks. The results in Fig. 8 reveal all the cracks contained either zinc or a mixture of zinc and copper. The 


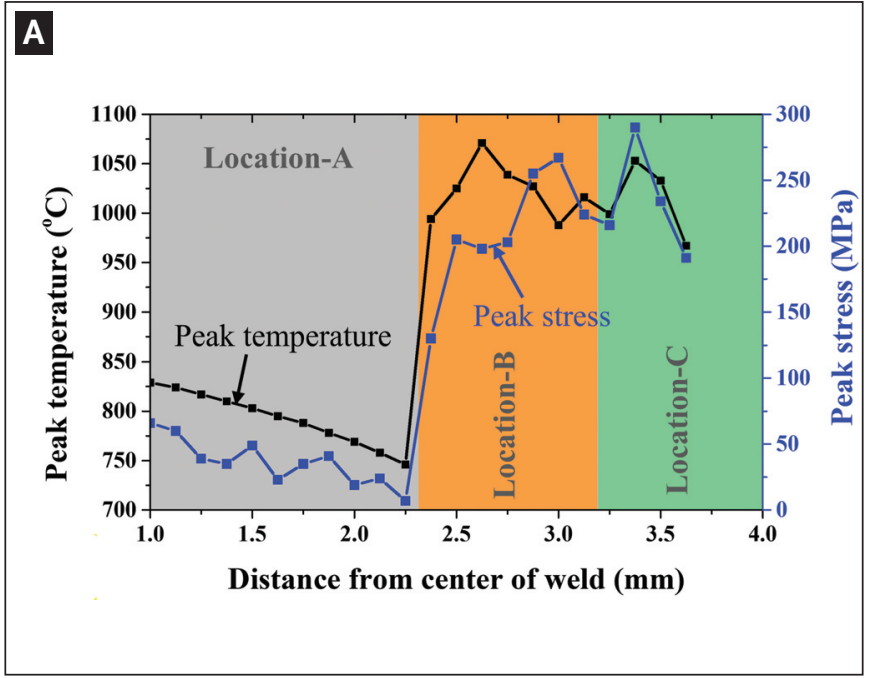

Fig. 7-Peak temperature and peak stress: A - Locations $A$, $B$, and $C ; B-$ location $D$ obtained using SORPAS.

zinc content at the root of all the cracks near the surface was observed to be around 80 at.- $\%$ of zinc. The tip of the crack at location A contained less amount of zinc, around 5 at.-\%; other crack types contained 30-40 at.-\% zinc at the crack tip. It is important to see that the cracks at location A contained a considerable amount of copper also. In location A, zinc melted and reacted with the solid copper and was trapped under the near-flat surface of the dome-shaped electrode and exhibited a high concentration of copper. On the other hand, the cracks at the other locations were characterized with less or no copper. The amount of copper kept on decreasing from $A$ to $B$ to $C$ as the contact with the copper electrode was reduced. Location $\mathrm{D}$, without any physical contact with the copper electrode, encountered a copperfree region. Zinc deposition was characterized from micro images and shown in Fig. 9, which was taken from each cracking area. The amount of zinc in location B was significantly less due to the squeeze out of zinc toward the periphery $(C)$ by the action of the electrode during welding. The melted and squeezed-out zinc from the shoulder area (B) finally deposited in the peripheral area $(C)$. This zinc pile-up can potentially provide a surplus amount of liquid zinc during the crack formation. It can be summarized that the zinc and copper present at different locations depended on the temperature and the contact condition with the electrode, and the temperature was further controlled by the contact condition with the electrode and the heat input as observed in the previous section.

\section{Microstructure at Various Locations}

Figure 10A-D shows the microstructure of various crack locations. Basically, two inferences can be drawn from the microstructure: firstly, the peak temperature at the root (surface) of each crack location; and, secondly, the microstructural features such as phases at the roots of the cracks. The phase fractions of ferrite in the base metal and various crack locations in the weld $(8.0 \mathrm{kA})$ are tabulated in Table 2.

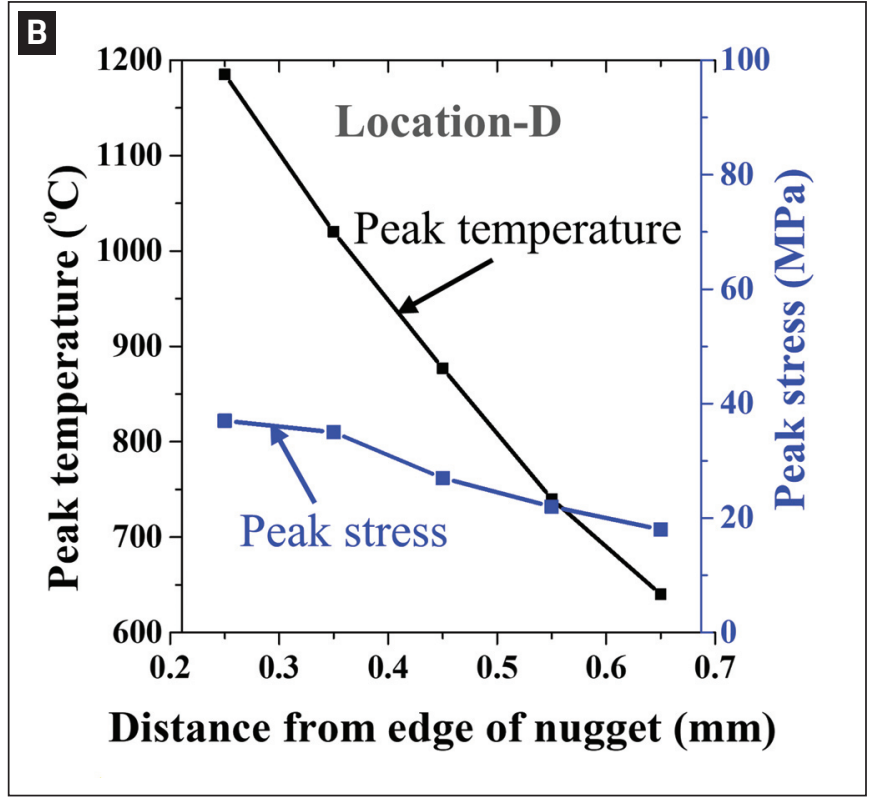

The phases adjacent to the cracks can be explained using the equilibrium phase fraction obtained from the ThermoCalc software shown in Fig. 10E. According to Fig. 10, location A consisted of ferrite, martensite, and bainite; however, the fraction of ferrite is less than that of the base metal, as in Table 2. The presence of martensite indicates the temperature in this region must have risen above the $A_{1}$ temperature $\left(685^{\circ} \mathrm{C}\right.$, as shown in Fig. $\left.10 \mathrm{E}\right)$, thereby forming austenite, which transformed into martensite on rapid cooling. Hence, the area consisted of a higher fraction of the martensite phase and a lower fraction of the ferrite in comparison with the base metal. It is also inferred that the peak temperature reached well above $685^{\circ} \mathrm{C}$ and reached an intercritical temperature so that the microstructure became ferrite and austenite.

In location $\mathrm{B}$, the amount of ferrite further reduced to a fraction ranging from 0 to 0.05 , indicating that some portion of location B consisted entirely of martensite, but the other portions contained some amounts of ferrite as well. However, the peak temperature at all the points in location $B$ exceeded above $A_{3}\left(898^{\circ} \mathrm{C}\right)$; hence, the microstructure was supposed to consist of only martensite. The reason for the presence of untransformed ferrite in location $B$ with peak temperature above $A_{3}$ can be the high heating and cooling rates. The time was not adequate for the diffusion-aided transformation of ferrite into austenite even though the temperature exceeded $A_{3}$. On the other hand, $C$ and D consisted only of the martensite phase. This shows the peak temperature at these locations must have been greater than the $\mathrm{A}_{3}$ temperature, indicating that the locations consisted only of the austenite phase at that temperature, which later transformed into martensite during cooling. However, coarser prior austenite grains in D specify that the peak temperature in this region was higher than that of $C$. It is worth noting that the peak temperatures at different locations inferred from the microstructure are in good agreement with the peak temperatures obtained using SORPAS simulation of the RSW process. 

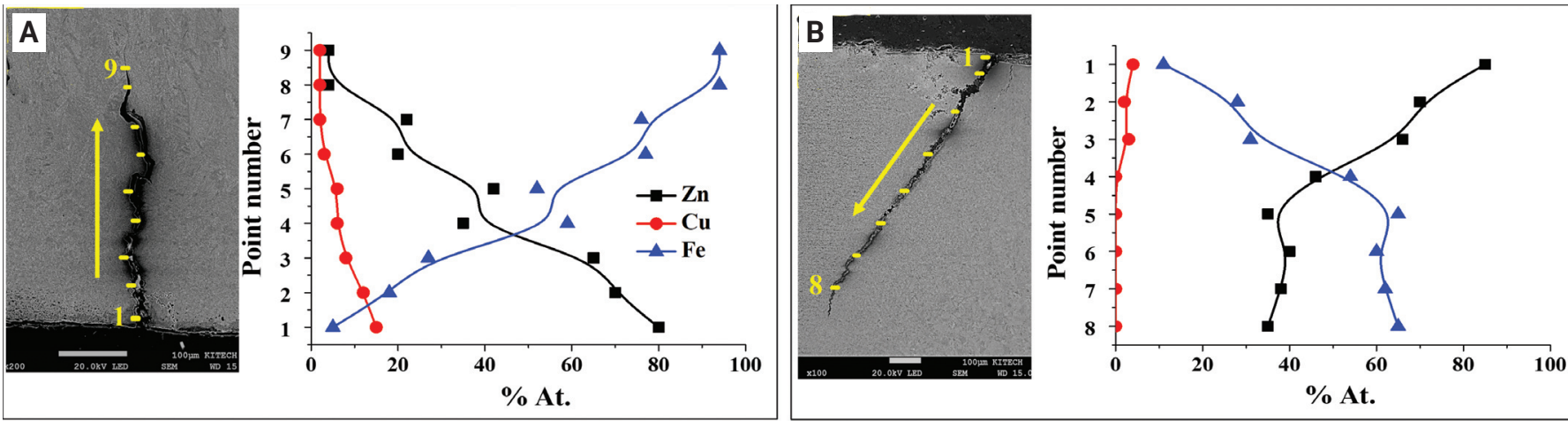

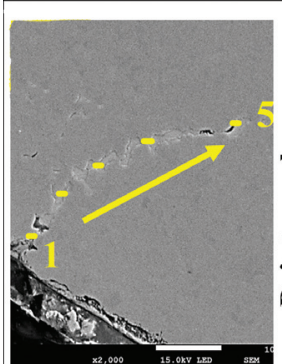

C
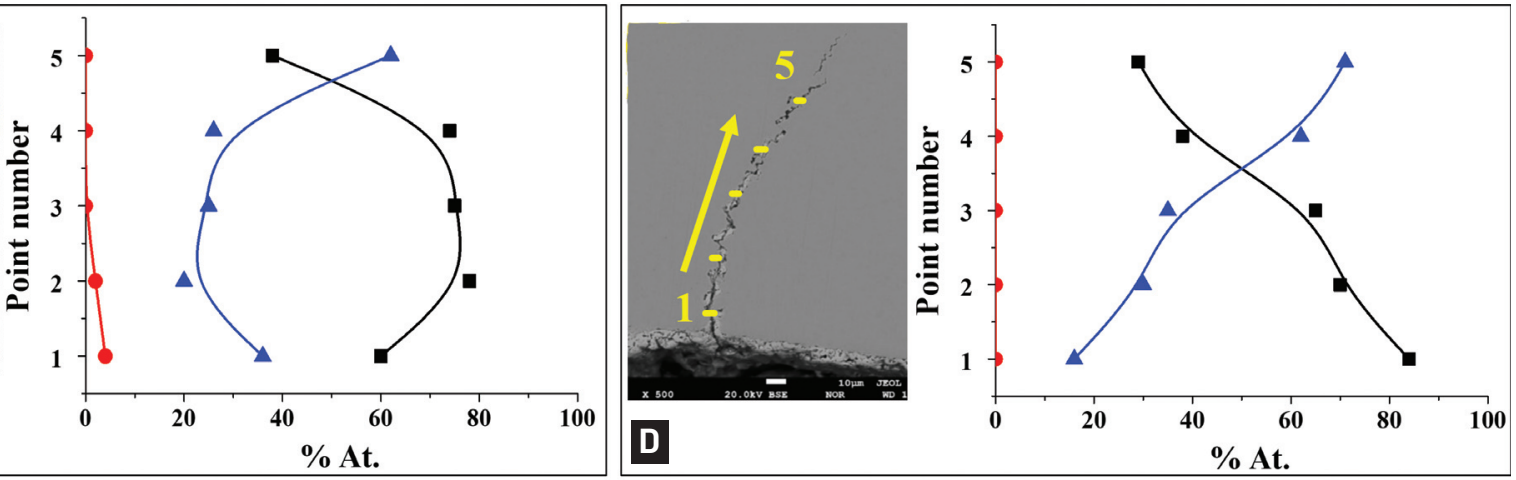

Fig. 8 - Distribution of $\mathrm{Zn}, \mathrm{Cu}$, and Fe along the LME cracks: $A$ - Location $A ; B$ - location $B ; C$ - location C; D - location D.

\section{Discussion}

\section{Stress Development}

Investigating the development of stress at various crack locations is important because the tensile stress is a major factor affecting LME cracking. Different stress states (magnitude and direction) are induced at different crack locations as a result of thermal-mechanical interactions during RSW. Owing to the high cooling rate through the electrodes, the temperature gradient is high, particularly in the vicinity of the electrodes. Subsequently, large thermal stresses are developed in the welds during heating and cooling (Ref. 32). Therefore, thermal-mechanical analysis is performed using simplified assumptions wherein the development of stress is qualitatively investigated using the thermal history obtained from the simulation (Refs. 32-34).

The development of stress in the nodes shown in Fig. 6 can be explained with the help of the schematic diagrams shown in Fig. 11, wherein the direction and magnitude of the instantaneous stress are indicated by the direction and number of arrows. As can be seen, there are various events and developments of instantaneous and net stresses during the different stages (squeeze time, weld time, and hold time) of RSW. To better understand the development of stress, the nodes are considered in the order of $\mathrm{P}_{1}$ to $\mathrm{A}$, that is, from the base metal toward the electrode.

As shown in Figs. 6 and 11, compressive stresses are developed at the nodes at the $\mathrm{E} / \mathrm{S}$ interface during the initial stage of heating during weld time. In $\mathrm{P}_{1}$, compressive stress was developed and slowly increased during the weld time. Typically, solid metal is subjected to stresses with nonuni-
Table 2 - Fraction of Ferrite in the Microstructure of Base Metal and Various Crack Locations

\begin{tabular}{cc} 
Location & Fraction of Ferrite \\
\hline Base metal & 0.52 \\
Location A & 0.18 to 0.31 \\
Location B & 0 to 0.05 \\
Location C & 0 \\
Location D & 0 \\
\hline
\end{tabular}

form or nonlinear temperature variation (Ref. 35). The temperature of the node increased with the weld time, and resulted in the expansion of the solid metal and subsequent generation of compressive stress during weld time (Refs. 32, 34 ). The value of the maximum compressive stress at the nodes increased while moving from node $\mathrm{P}_{1}$ toward the electrode, and finally reached the value of $240 \mathrm{MPa}$ at node B. In fact, the temperature, temperature gradient, and mechanical constraint from the electrode loading at the nodes increased while moving toward the electrode. Therefore, under high constraints, the nodes closer to the electrode underwent severe restriction against the thermal expansion; hence, higher compressive stresses were developed during heating.

However, during heating, less compressive stress developed at the nodes away from the electrode because the solid metal could expand more freely with less constraints. When the current was shut off (hold time), the heating terminated and cooling started, which caused the development of tensile stress in $\mathrm{P}_{1}$ owing to the contraction of the solid metal. The development of tensile stress as a result of cooling was ob- 


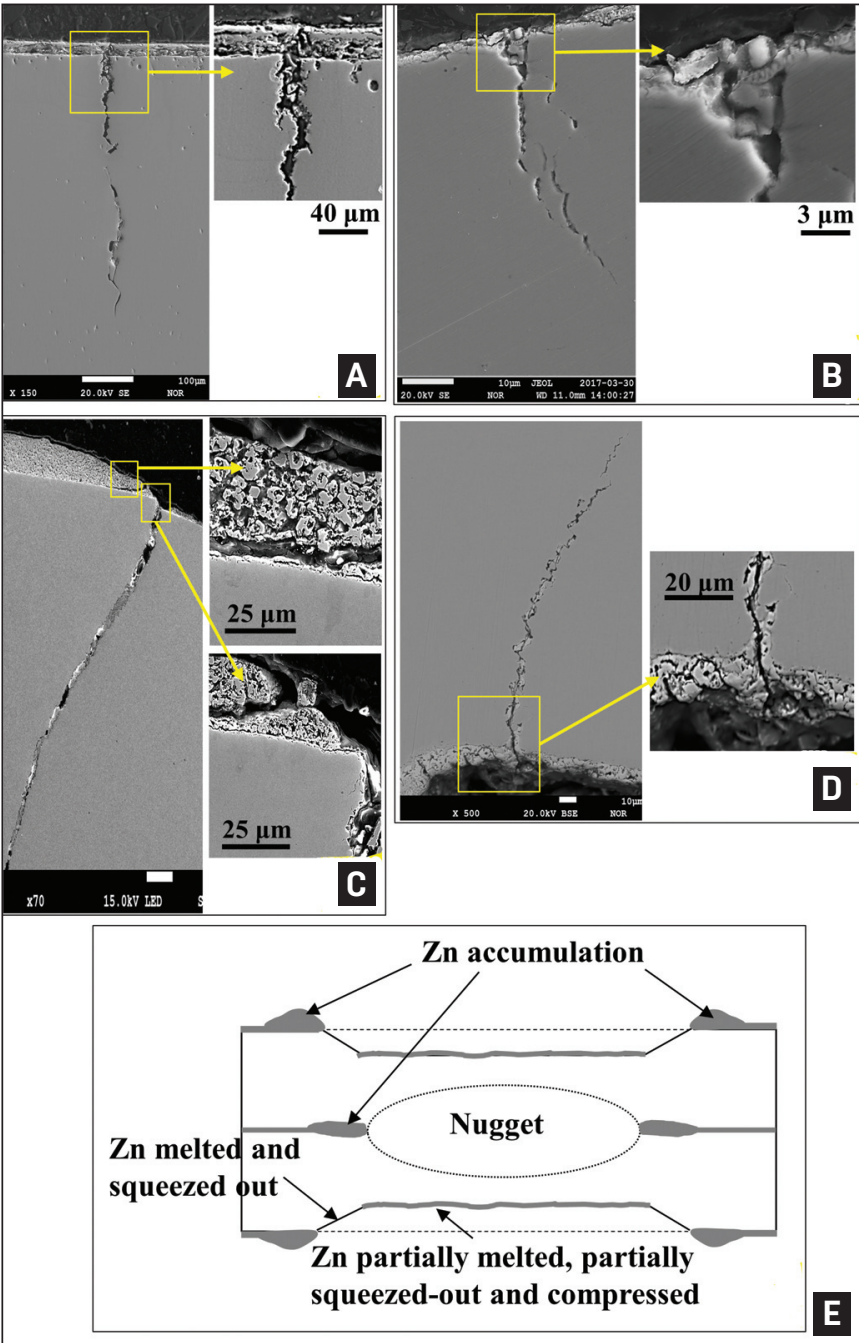

Fig. 9 - Zinc coating after RSW at: A - Location A; B - location $B$; $C$ - location $C$; $D$ - location $D ; E$ - schematic representation of distribution of solid and molten zinc from the coating during RSW.

served in these nodes, and the magnitude of the developed tensile stress was higher for the nodes closer to the electrode. The cooling rate and constraints were higher for the nodes closer to the electrode, which resulted in the formation of tensile stress within a very short period of time.

Unlike node $\mathrm{P}_{1}$, the compressive stress at nodes $\mathrm{C}$ and $\mathrm{B}$ attained the maximum value before the end of the weld time; then, tensile stresses were induced at the nodes. In addition to providing a mechanical constraint, the welding electrodes also act as a massive heat sink that can dissipate enormous amounts of heat away from the weld. During weld time, the electrode was pushed into the steel, thus creating electrode indentation and generating a new thermal contact between the weld surface and the electrode at the edge of the E/S interface, which is considered a mechanical collapse (Ref. 36). The new thermal contact enabled the electrode to conduct more heat away from the region, which resulted in an instantaneous temperature drop close to the edge of the $\mathrm{E} / \mathrm{S}$ interface. This sudden temperature drop close to the E/S contact point with a high nonlinear temperature gradient
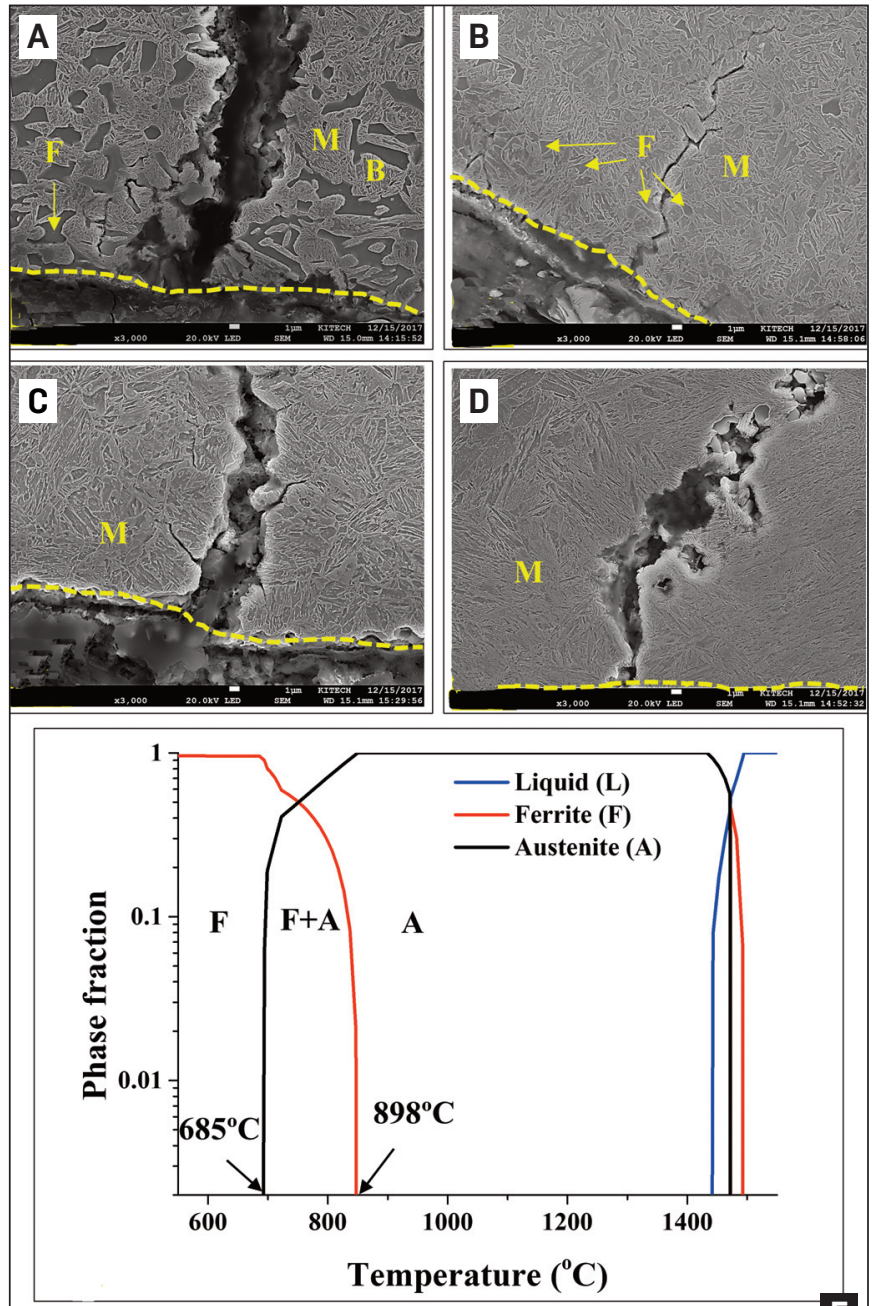

Fig. 10 - Microstructure: A - Location A; B - location B; C location $C ; D$ - location $D ; E$ - property diagram of the steel from Thermo-Calc (F: ferrite; M: martensite; B: bainite).

led to the instantaneous development of tensile stress (Ref. 36). Consequently, the net stress became tensile as the magnitude of tensile stress overcame the magnitude of existing compressive stress. Tensile stress was induced in node $C$ during the major portion of hold time, and then slowly decreased to relieve all stresses from the solid metal.

At node B, the development of net tensile stress within the weld time was observed, as similar to that of node $C$. However, the nature of stress at node $\mathrm{B}$ changed again as large compressive stress was induced toward the end of the weld time, which made the net stress compressive - Figs. 6 and 12. At this moment, the annular region of the electrode came into physical contact with node B (mechanical collapse) and exerted high compressive stress. It has been previously confirmed that the compressive stress at the annular region close to the edge of the $\mathrm{E} / \mathrm{S}$ interface is higher than that at the center of the $\mathrm{E} / \mathrm{S}$ interface (Ref. 37). The stress singularity obtained in the sheet at the edge of the E/S interface was perceived as the reason for the particular stress profile of the E/S interface. Compressive stress developed at the node wherein the mechanical collapse occurred, whereas tensile stress developed at the node to the 


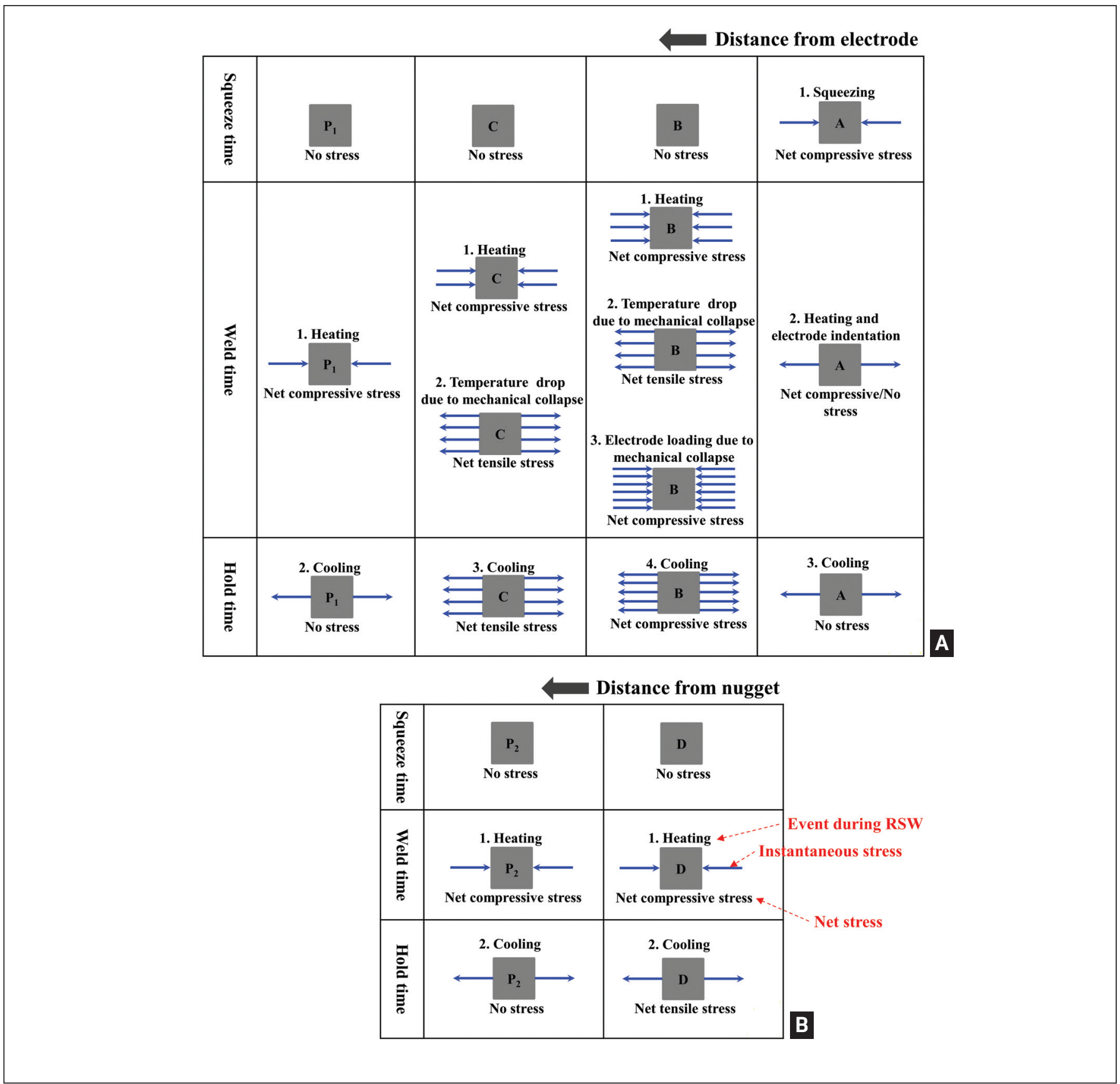

Fig. 11 - Schematic representation of the stress development at various locations during RSW: A - Nodes at the E/S interface; B - nodes at the $S / S$ interface.

immediate right of the mechanically collapsed node. Therefore, the mechanical collapse first created tensile stress and then compressive stress at location $\mathrm{B}$, while it only produced tensile stress at location $C$. During the hold time, tensile stress was induced owing to the fast cooling of the solid metal. However, the magnitude of the induced tensile stress during the hold time was still lower than the magnitude of the previously induced compressive stress, and this resulted in a net compressive stress - Fig. 11.

The stress development at locations B and C was visualized with the help of the stress distribution (Fig. 12) at different weld time instants. Four nodes (B1, B2, B3, and B4) from location $B$ and one node $(C)$ from location $C$ were considered in this study. Each node (e.g., B2) reached a maximum tensile stress owing to the temperature drop and nonlinear temperature distribution at the edge of the E/S interface. Then, the nodes underwent an instantaneous extinction of tensile stress as soon as the surface of the electrode touched the sheet, that is, when mechanical collapse occurred. Subsequently, the next node (e.g., B3) attained the maximum stress. This action continued to the following shoulder points (B4 and so on) until it reached the peripheral point ( $C$ of location $C$ ). Thus, location $B$ formed at the weld surface where the electrode surface did not initially 


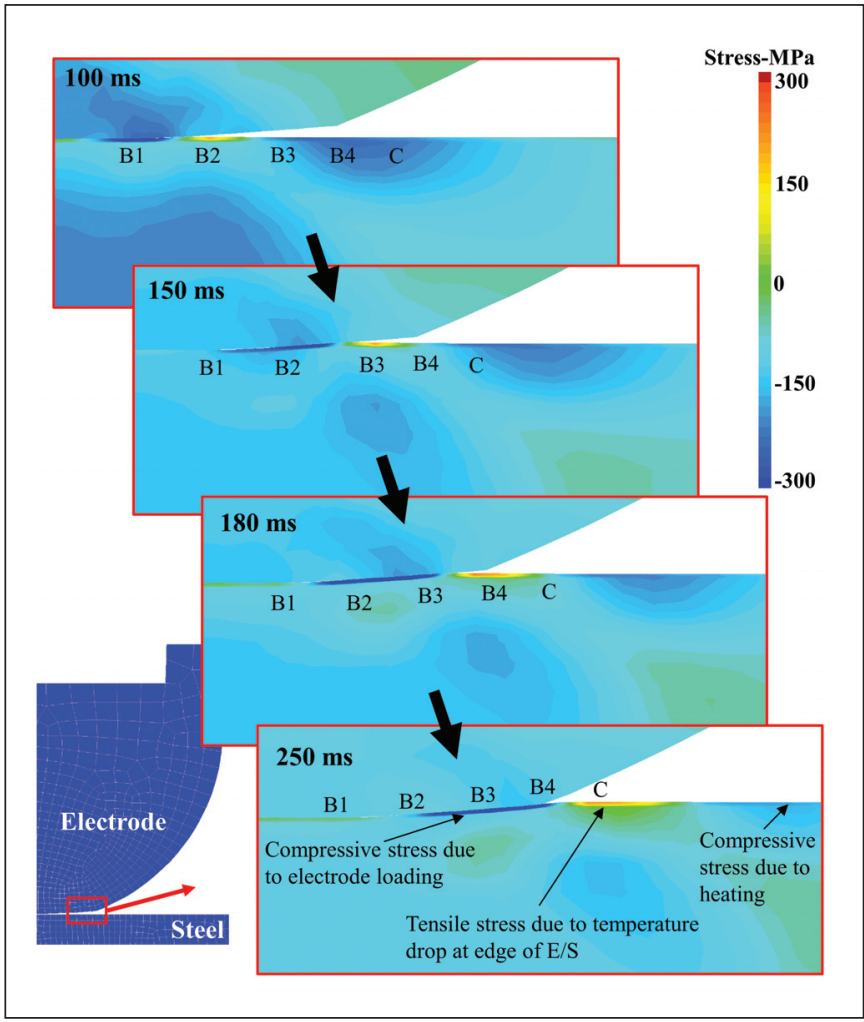

Fig. 12 - Stress developed in locations B and C is visualized using SORPAS stress field simulation.

make direct contact with the sheet. Consequently, a gap developed between the electrode and the steel sheet, as in the case of the peripheral area, and led to the increase of thermal stress. However, the gap instantly disappeared when mechanical collapse occurred, which resulted in the sudden decrease of tensile stress.

Node A existed in the electrode indentation region during the squeeze time, weld time, and hold time. During the squeeze time and weld time, the stresses at this node were compressive in nature, as has been reported by previous studies (Refs. 18, 36, 38). However, the magnitude of the compressive stress decreased with the increase of weld time as the contact area at the E/S interface increased (Ref. 37). Then, the stress became tensile during the hold time as tensile stress developed in the solid metal owing to the fast cooling.

The development of stress at location $\mathrm{D}$ (node $\mathrm{D}$ ) can be explained in the same manner as that of node $\mathrm{P}_{1}$. During the weld time, compressive stress developed owing to the heating and expansion of the solid metal at nodes $\mathrm{P}_{2}$ and $\mathrm{D}$. Tensile stress with lower magnitude than the compressive stress was induced at node $\mathrm{P}_{2}$ during the hold time as the solid metal contracted against the constraints and led to the development of a net compressive stress. Moreover, higher tensile stress was induced at D, owing to the solidified nugget constraints, and resulted in the development of net tensile stress. However, it has been previously reported that abnormal process conditions, such as electrode tilting, a gap between the sheets, and so on, can induce high tensile stress in the S/S interface (Refs. 12, 31, 39).
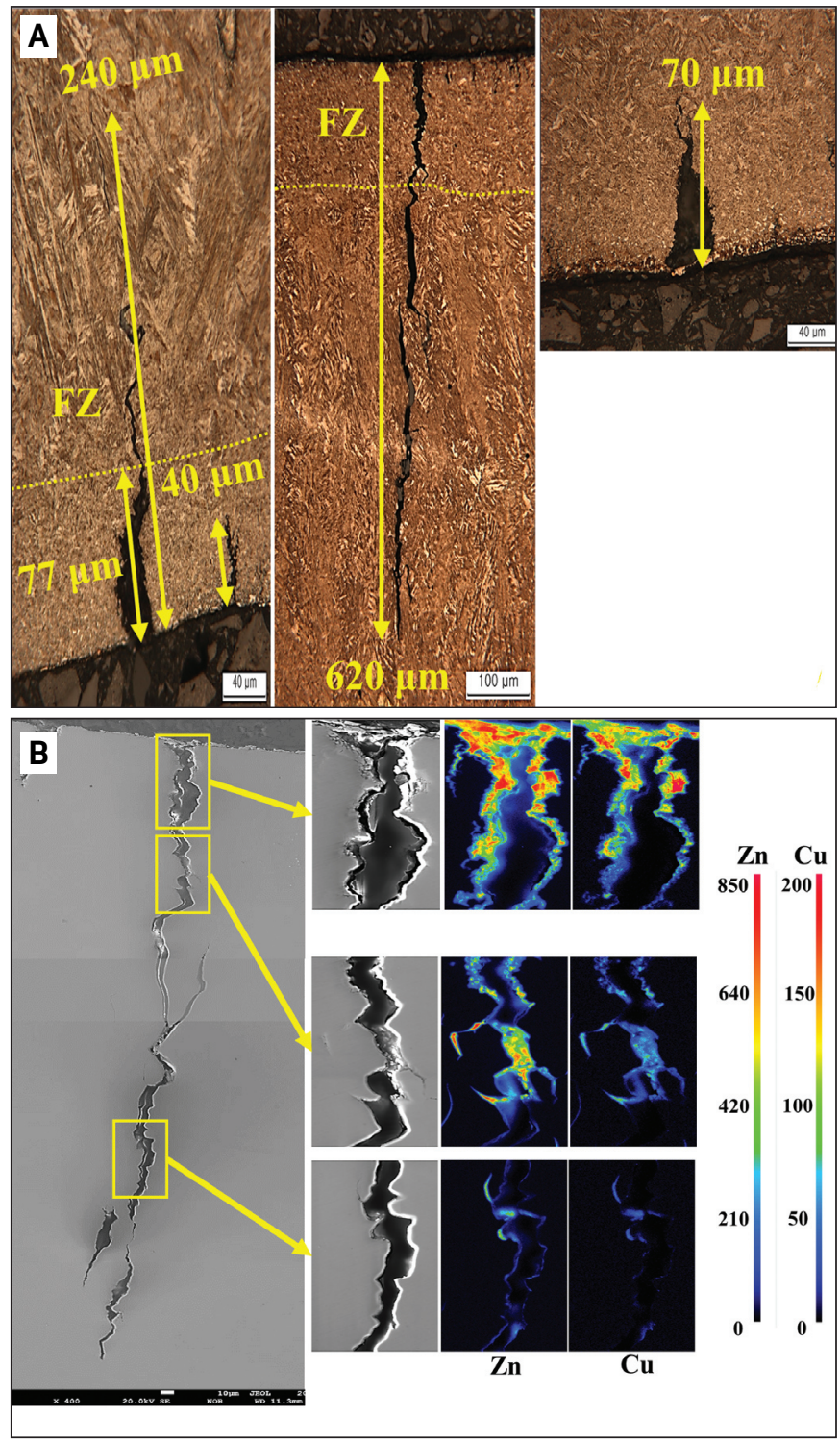

Fig. $13-A-$ Optical images of small and large LME cracks at location $A ; B$ - EPMA elemental mapping of a large LME crack at location $A$, which propagated deep into the $F Z$.

During RSW, stress fields with different directions and magnitudes develop at various crack locations owing to the occurrence of several events - Fig. 11. These events become more remarkable and the stress field becomes more complex in the direction toward the electrode (from $\mathrm{P}_{1}$ to $\mathrm{A}$ ), which illustrates the influence of the electrode on stress development. The events responsible for the variation in the nature and magnitude of stresses are 1 ) heating during weld time, which induces compressive stresses; 2) sudden temperature drop owing to the mechanical collapse at the edge of the E/S interface, which induces tensile stress; 3 ) electrode loading owing to the mechanical collapse at the edge of the E/S interface, which induces compressive stresses; and 4) cooling during hold time, which induces tensile stresses. However, the magnitude of these stresses is determined by the temperature, heating rate, cooling rate, temperature gradient, degree of constraints, and so on. Therefore, it can be concluded that the electrode influ- 

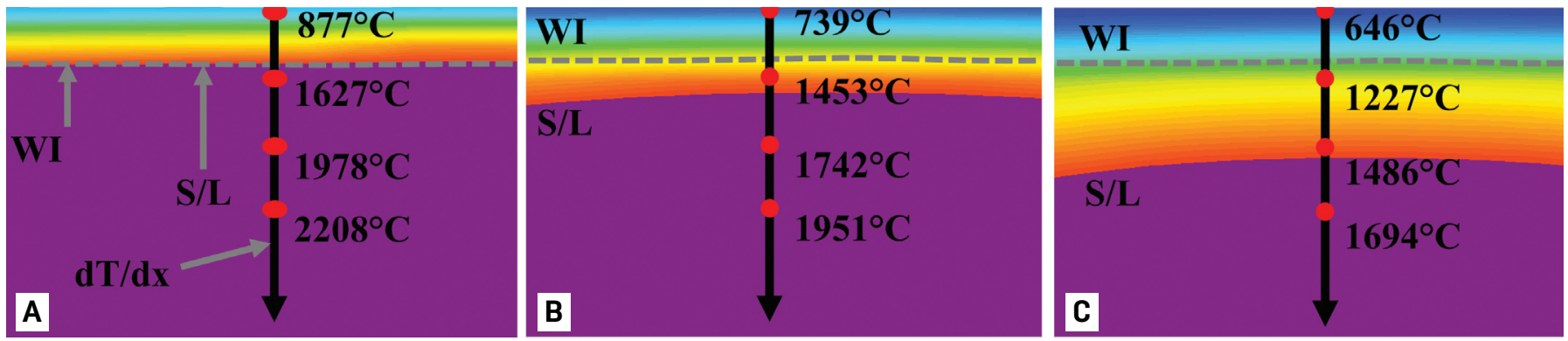

Fig. 14 - Temperature distribution at the center of the weld near the surface along the direction of the temperature gradient $(\mathrm{dT} / \mathrm{dx})$ : $A$ - Weld time $=300 \mathrm{~ms} ; \mathrm{B}$ - hold time = $50 \mathrm{~ms} ; \mathrm{C}$ - hold time = $100 \mathrm{~ms}$ (Wl: weld interface; S/L: solid/liquid interface; FZ: fusion zone; $d T / d X$ : temperature gradient).

ences the stress development in four ways: 1) acts as a mechanical constraint against the expansion and contraction of the solid metal; 2) provides a high cooling rate and, hence, a high nonlinear temperature gradient at the E/S interface; 3) induces an instantaneous temperature drop at the edge of $\mathrm{E} / \mathrm{S}$ when mechanical collapse occurs; and 4) exerts compressive stress upon making physical contact with the solid metal.

\section{Thermal-Mechanical-Metallurgical Factors and Formation of LME Cracks at Various Locations: Types of LME Cracks}

The different locations exhibited different crack behavior (number of cracks, crack length, and crack orientation) and different thermal-mechanical-metallurgical features. Therefore, the LME cracks forming at various RSW locations can be classified according to the crack location as type-A, type$B$, type- $C$, and type-D cracks. To understand the mechanism of LME crack formation at various locations, it is important to investigate the factors affecting LME. The primary influencing factors are the microstructure, temperature, tensile stress magnitude, and availability of liquid zinc (Refs. 4, 6, $19,20,40)$. The austenite microstructure is reportedly the most favorable to LME cracking (Ref. 40). Amongst these factors, the availability of liquid zinc is essentially a function of temperature. When the temperature rises above the melting point of the galvannealed coating, liquid zinc is formed. Galvannealed coating mainly consists of $\delta-\mathrm{FeZn}_{10}$ as well as thin layers of $\Gamma-\mathrm{Fe}_{3} \mathrm{Zn}_{10}$ and $\zeta-\mathrm{FeZn}_{13}$ (Ref. 1). Therefore, the melting temperature of $\delta\left(665^{\circ} \mathrm{C}\right)$ can be considered as the melting temperature of the galvannealed coating (Ref. 41). In this study, the combination of these factors was considered and correlated with the crack features to clarify the mechanism of crack formation at various locations. A comparison of these factors at various RSW locations with a welding current of $8.0 \mathrm{kA}$ is presented in Table 3 .

For a given heat input $(8.0 \mathrm{kA})$, the factors affecting $\mathrm{LME}$ did not favor for the formation of large, type-A cracks. This indicates that other factors/phenomena were responsible for the abnormal cracking behavior. From the microimages of type-A cracks shown in Fig. 13A, it is obvious that larger cracks propagated into the FZ. However, smaller cracks were terminated before entering the FZ with a relatively smaller crack length. Therefore, it is concluded that the penetration of liquid metal and the resultant crack propagation interact- ed with the FZ, which resulted in the formation of large cracks.

Figure 13B shows the EPMA elemental mapping of a large crack propagating deep into the FZ. The crack contained a considerable amount of zinc and copper; however, the amount of zinc and copper continuously declined along the crack length, particularly inside the FZ. Therefore, it can be said that the crack propagation was caused entirely by zinc-assisted LME. The temperature fields at location A at the end of the weld time ( $300 \mathrm{~ms})$, and at the hold times of 50 and 100 ms, are shown in Fig. 14.

Compared with the LME crack shown in Fig. 13D, it is clear that, unlike the cracks in other locations, the crack propagation advanced in the direction parallel to the positive temperature gradient, that is, from a lower temperature to a higher temperature, and finally entered the FZ with a crack orientation of 90 deg to the surface. A high temperature gradient, which occurred as a result of the continuous contact with the water-cooled copper electrode, forced the crack tip to move from a lower temperature to a higher temperature with a high crack propagation rate. Figure 15 presents a detailed explanation for the formation of such large cracks.

In the HAZ, the liquid metal penetration and crack propagation can be observed through the grain boundary of the coarse grains, whereas in the FZ, the crack propagation occurs through the solidification grain boundary or solidification subgrain boundary - Fig. 15A. The stages of large crack formation are schematically described in Fig. 15B. During the weld time, liquid metal is formed at the E/S interface owing to the melting of zinc and its reaction with copper. Additionally, toward the end of the weld time or during the hold time, the liquid metal penetrates the steel along the grain boundaries to form intergranular cracks under high temperature and tensile stress. During the solidification (hold time) of the molten steel in the FZ, the liquid metal from the coarse-grained HAZ diffuses into the solidified FZ. The grain boundaries are continuous across the fusion boundary owing to the epitaxial nucleation and grain growth inside the FZ (Ref. 42). This creates a natural grain boundary pipeline from the HAZ into the FZ, which acts as a channel for the diffusion of liquid metal into the FZ. Additionally, tensile strain is induced in the fusion boundary and FZ during solidification, owing to solidification shrinkage and nonuniform thermal contraction. Consequently, a state similar to the solidification cracking prevails in the FZ with 

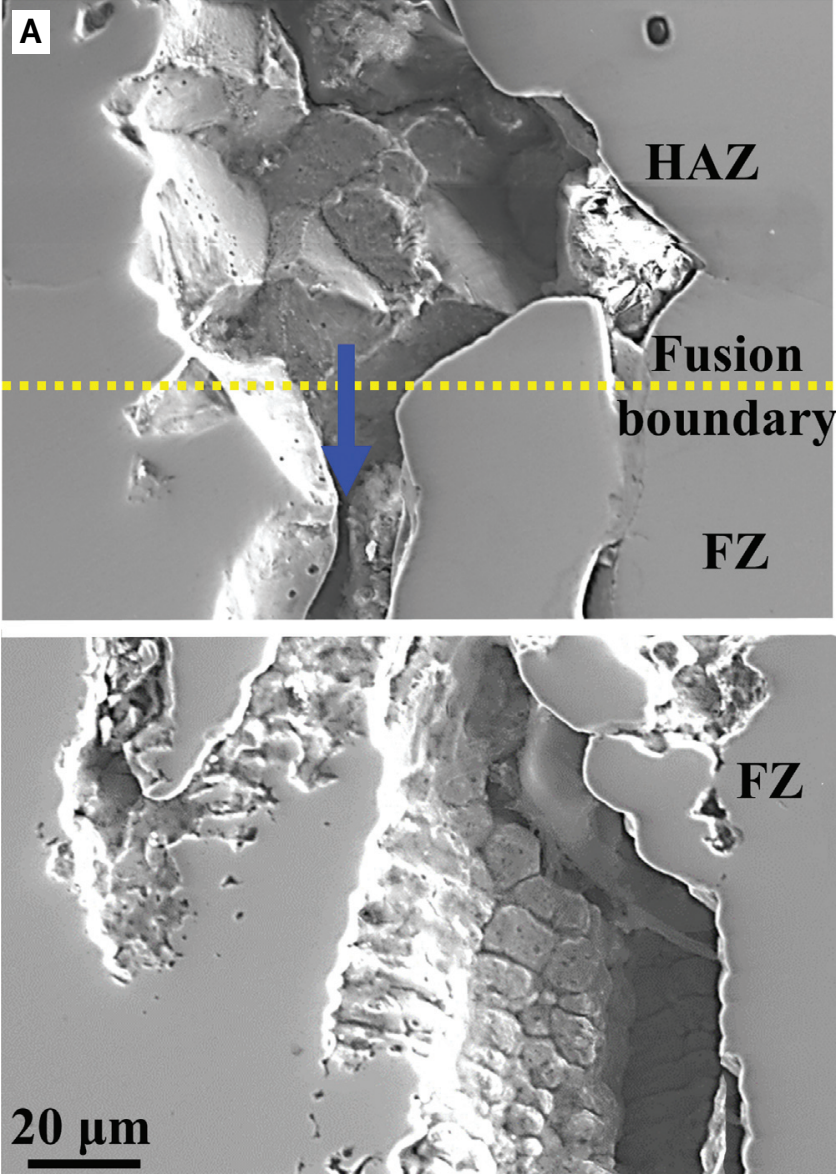

a liquid metal film separating the grain boundaries, that is, a mushy zone (Refs. 42, 43). Therefore, it can be inferred that the penetration of liquid metal and the interaction of crack propagation with the weld zone causes the formation of large-sized LME cracks in the center.

The results presented in Table 3 suggests type-B and type- $C$ cracks have similar features because locations $B$ and $C$ were subjected to high temperature and tensile stress. Figure 16 shows the cross-sectional SEM images of the type-B and type-C LME cracks in a weld produced with a welding current of $8.0 \mathrm{kA}$. In Fig. 16, it is clear that the crack length suddenly increased, but the number of cracks decreased when the crack type changed from B to $C$. As discussed in the Stress Development section, the existence of short-lived
B

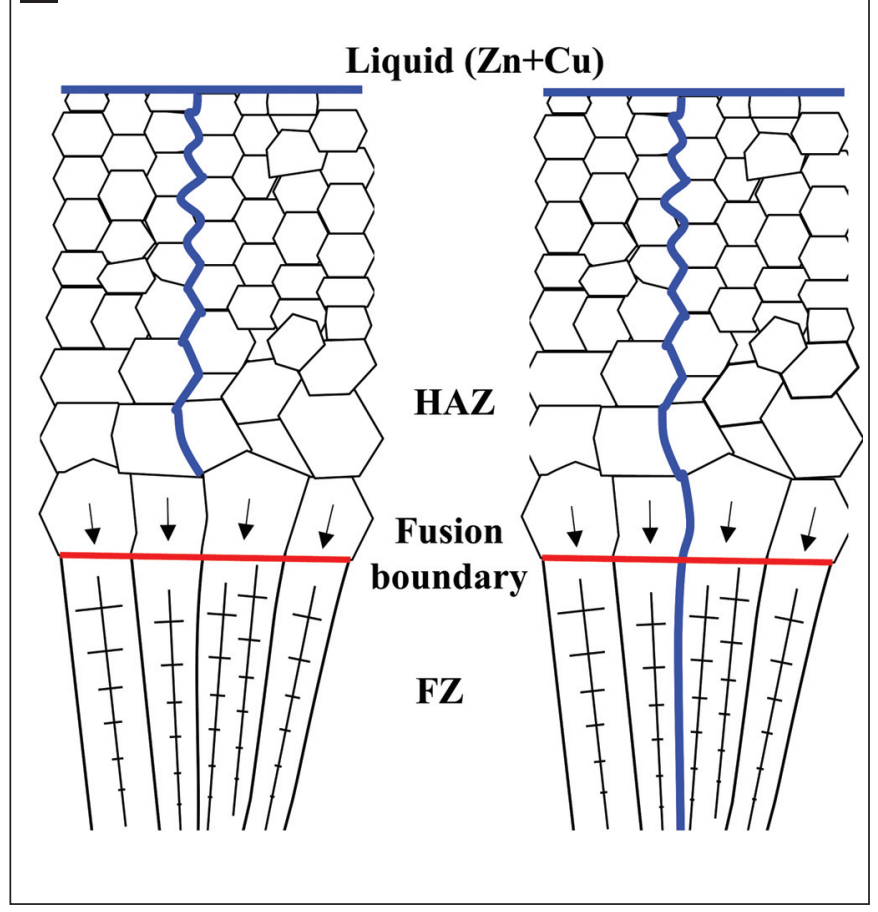

Fig. 15 - The formation of large, type-A LME cracks in the center of the weld: $A$ - SEM images showing the crack propagation through $H A Z$ and FZ; B - schematic representation of the stages of crack formation at location A (FZ: fusion zone; HAZ: heat-affected zone).

moving maxima should be considered to explain the difference in the formation of type-B and type-C LME cracks.

Interestingly, Figs. 12 and 16 are similar. In Fig. 16, numerous short cracks $(21-50 \mu \mathrm{m})$ were formed at location B, which correspond to the short-lived maxima (B2, B3, and B4) in Fig. 12. Additionally, the single and large, type-C crack corresponds to $C$ in Fig. 12. Therefore, it can be said that the time period during which the location is subjected to high temperature and tensile stress is an important influencing factor for the formation of LME cracks. The sudden temperature decrease after the maximum values had been reached resulted in limited time of exposure to the liquid zinc and tensile stress. In other words, the tensile stress and the availability of liquid zinc were interrupted during weld-

Table 3-Microstructural Observations, Crack Features and Corresponding Temperature, and Stress Regimes for Various LME Crack Types (A: Austenite; F: Ferrite)

\begin{tabular}{|c|c|c|c|c|c|}
\hline & $\begin{array}{l}\text { Maximum Crack } \\
\text { Length }(\mu \mathrm{m})\end{array}$ & $\begin{array}{l}\text { Number of } \\
\text { Cracks }\end{array}$ & $\begin{array}{l}\text { Microstructure at Peak } \\
\text { Temperature }\end{array}$ & $\begin{array}{l}\text { Peak Temperature } \\
\left({ }^{\circ} \mathrm{C}\right)\end{array}$ & $\begin{array}{l}\text { Peak Stress- } X \\
(\mathrm{MPa})\end{array}$ \\
\hline Location A & $760 \pm 60$ & $7 \pm 2$ & $A+F$ & 829 & 66 \\
\hline Location C & $960 \pm 205$ & $3 \pm 2$ & A & 1053 & 290 \\
\hline Location D & $70 \pm 7$ & $2 \pm 1$ & $A$ & 1185 & 37 \\
\hline
\end{tabular}

Location

\section{From OM and SEM Images}

88-s WELDING JOURNAL / MARCH 2020, VOL. 99 

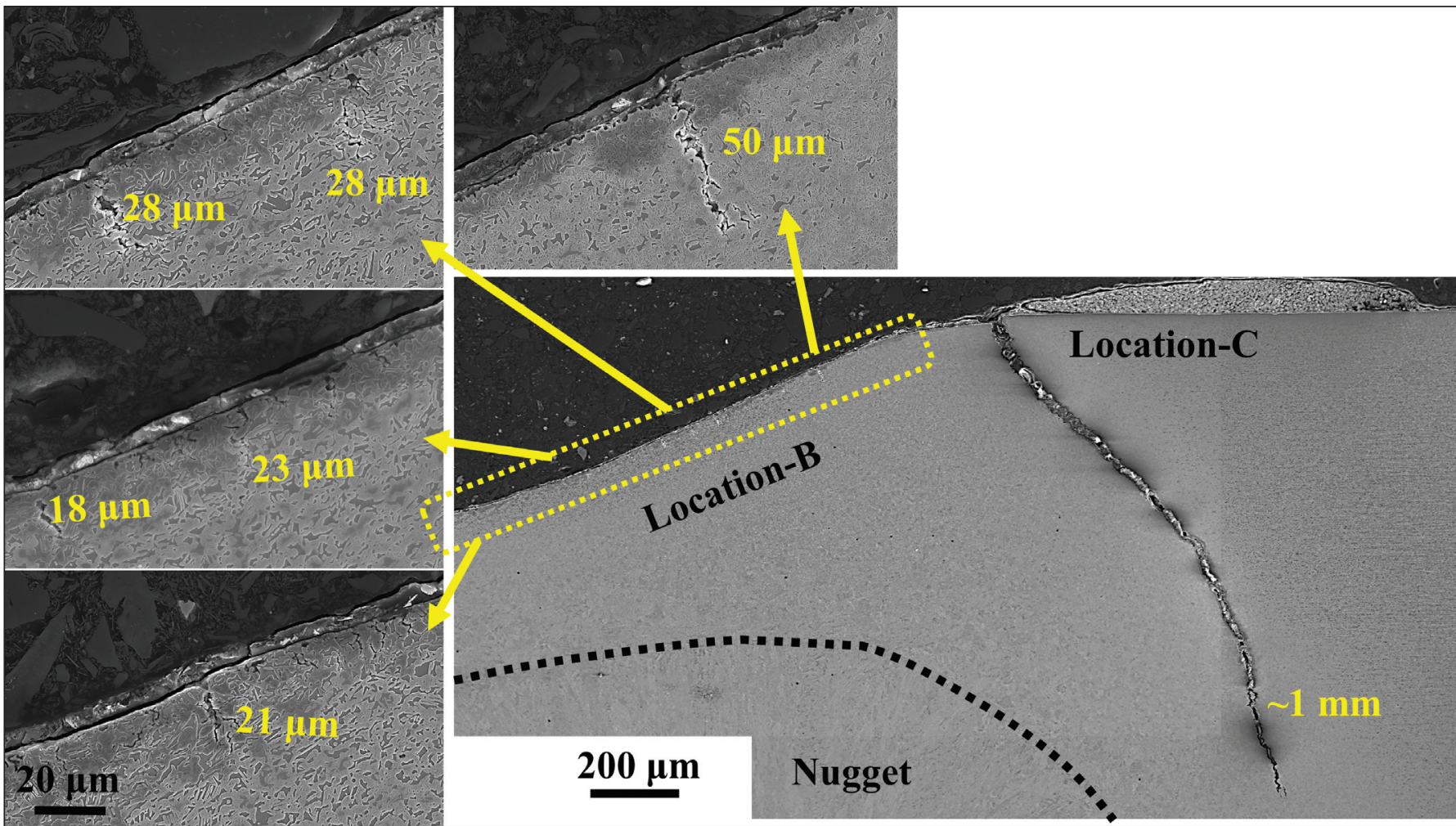

Fig. 16 - Cross-sectional view of small, type-B LME cracks at location B and a large, type-C LME crack at location C.

Table 4 - Instant of Initiation, Propagation, and Termination of Various LME Crack Types (WT: Weld Time; HT: Hold Time; OT: Off Time)

\begin{tabular}{cccc} 
Type of LME Crack & Initiation & Propagation & Termination \\
\hline Type A & WT or HT & HT & HT or OT \\
Type B & WT & WT & WT \\
Type C & WT & WT and HT & HT or OT \\
Type D & HT & HT and OT & OT
\end{tabular}

ing; hence, the crack propagation ceased at a relatively low crack length. The same action continued as the electrode indentation increased to produce numerous type-B cracks in the shoulder region of the weld surface.

Therefore, two additional factors must be considered, namely the time of exposure to liquid zinc $\left(\Delta \mathrm{t}_{\mathrm{LZ}}\right)$ and the time of exposure to tensile stress $\left(\Delta t_{\mathrm{TS}}\right)$, when examining the LME cracks in the RSW. Here, $\Delta \mathrm{t}_{\mathrm{LZ}}$ primarily indicates the availability of liquid zinc and the time required for the penetration of zinc, and is defined as the time interval over which a specific location is exposed to liquid zinc, which increases the location's temperature higher than the melting temperature of the GA coating $\left(665^{\circ} \mathrm{C}\right)$. Furthermore, $\Delta \mathrm{t}_{\mathrm{TS}}$ is defined as the time over which a specific location is subjected to tensile stress and indicates the duration of tensile stress in the initiation and propagation of the LME crack.

Figure 17 shows the time of exposure to liquid zinc and the tensile stress for various crack locations. Owing to the lower values of $\Delta \mathrm{t}_{\mathrm{LZ}}$ and $\Delta \mathrm{t}_{\mathrm{TS}}$, short type-B cracks were formed even though the peak temperature and peak stress were high. In previous reports, type-B cracks were either excluded or considered along with the cracks forming in the peripheral region. In this study, type B was considered as a separate category because it exhibited unique features compared with other crack types. Additionally, the thermalmechanical characteristics at this crack location were different than those at other locations.

As presented in Table 2 and Fig. 17, the combination of all the necessary factors for LME cracking satisfies the criteria for large, type- $C$ cracks in the peripheral area. Similar observations have been reported by Ashiri et al., and this area was termed as the supercritical area for LME (Ref. 13). Location $C$ was not only subjected to high temperature and thermal stress, but also exhibited higher $\Delta \mathrm{t}_{\mathrm{LZ}}$ and $\Delta \mathrm{t}_{\mathrm{TS}}$. Moreover, the microstructure consisted only of LME-sensitive austenite. Thus, it allowed sufficient time for the liquid zinc to penetrate deep into the steel sheet through the austenite grain boundaries at higher tensile stress. Additionally, a significant amount of zinc was deposited at the root of the cracks as a result of the melting and squeezing out of zinc from the shoulder area (location B) during welding, and its subsequent accumulation in the peripheral (C) area (Fig. 9). This zinc pile-up could potentially provide a surplus of liquid zinc during crack formation. Similar to type $B$, type $C$ was also strongly influenced by the time of exposure, which illustrates the time dependency of these cracks.

As shown in Fig. 4, a few short type-D cracks occurred at the $\mathrm{S} / \mathrm{S}$ interface only at relatively higher currents (7.5 and $8.0 \mathrm{kA}$ ). As presented in Table 3 and Fig. 17, except for the tensile stress, all other required factors were satisfied for the LME at location D. A recent report has confirmed 

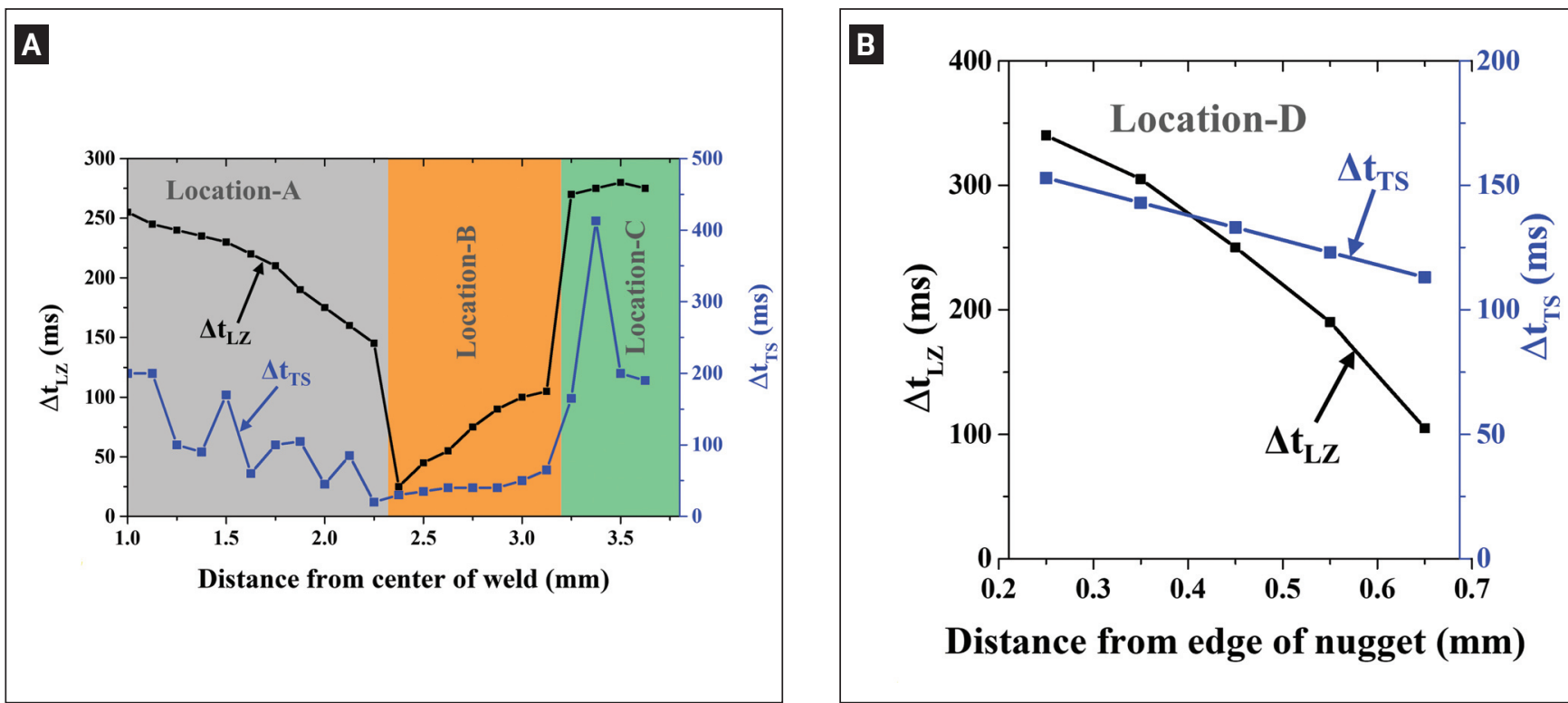

Fig. 17 - Time of exposure to: $A-$ Liquid zinc $\left(\Delta t_{L Z}\right) ; B$ - tensile stress $\left(\Delta t_{T S}\right)$.

the presence of large tensile stress (approximately 250 $\mathrm{MPa}$ ) in the HAZ, which exists in the S/S interface during the hold time of RSW with an electrode tilting of $7 \mathrm{deg}$ (Ref. 31). This eventually causes the formation of large LME cracks at the S/S interface. A similar observation was made by Beal et al. (Ref. 39), who reported that additional tensile stress was produced at location D by inserting spacers between the sheets during RSW. From these findings, it can be inferred that abnormal process conditions, such as electrode tilting, a gap between the sheets, and so on, can induce severe extrinsic tensile stress in the S/S interface (Refs. 12, 31, 39). In this study, the cracks formed owing to the tensile stress arising from any of the above-mentioned practical instabilities, in addition to the high temperature and availability of liquid zinc.

The investigation of the formation of various LME crack types revealed that crack initiation, crack propagation, and crack termination of the various crack types occurred at different instants with respect to the process time, as summarized in Table 4 . The process time consisted of the weld time (WT), hold time (HT), and off time (OT), which is the time after the removal of the electrode force from the weld. The initiation and propagation instants of the cracks are very significant when dealing with the elimination of LME cracks, which can be suppressed if the initiation and propagation of the crack is eliminated or delayed.

In conclusion, different types of LME cracks formed at various locations owing to the synergetic effect of temperature, stress, microstructure, and time of exposure. The difference in the thermal-mechanical-metallurgical characteristics of the spot welds originated from 1) the nature of the contact condition between the electrode and the steel sheet; 2) the heat input (welding current); and 3) the field variables. Additionally, the time dependency of the LME cracks was revealed by the relationship between the time of exposure $\left(\Delta \mathrm{t}_{\mathrm{LZ}}\right.$ and $\left.\Delta \mathrm{t}_{\mathrm{TS}}\right)$ and the LME cracks, particularly type-B and type- $C$ cracks. Electrode tilting, the gap between the sheets, clamping conditions, and so on were the field variables that can potentially provide extrinsic tensile stress in the S/S interface. This study highlighted the need for a detailed investigation into the effect of these field variables on type-D LME cracking, which will be the subject of future work.

Moreover, it is essential to further investigate the impact of various types of LME cracks on the weld joint integrity. To establish the safety specifications for various types of cracks, it is required to create various crack types with different sizes. Because it is difficult to induce a particular crack type with different sizes, the finite element method should be used to simulate cracks with different sizes. Then, failure analysis should be used to correlate the crack length with the mechanical properties. In the above mentioned investigations, type- $B$ cracks can be disregarded because small-sized type-B cracks do not affect the mechanical properties of spot welds.

\section{Conclusion}

Liquid metal embrittlement cracks at various locations in the $\mathrm{Zn}$-coated $\mathrm{CP}$ resistance spot welds were characterized. Different types of LME cracks were formed at various locations owing to the synergetic effect of the thermal-mechanical-metallurgical characteristics of the corresponding locations. Specifically, the difference in temperature, tensile stress, microstructure, and the availability of liquid zinc at various locations caused the formation of various types of LME cracks with different characteristics. It is also revealed that the LME cracking in RSW is strongly influenced by the time of exposure to liquid zinc $\left(\Delta \mathrm{t}_{\mathrm{LZ}}\right)$ and the time of exposure to tensile stress $\left(\Delta t_{\mathrm{TS}}\right)$, which shows the time dependency of these cracks.

The various types of LME cracks are as follows:

- Type A: They were formed as large LME cracks (up to $800 \mu \mathrm{m})$ at the center of the weld surface due to the penetration of liquid zinc and the interaction of the crack with 
the FZ. The FZ, adjacent to the surface, upon solidification, allowed the easy penetration and propagation of $\mathrm{Zn}$ LME cracks through long and continuous solidification grain boundaries and subgrain boundaries owing to the tensile strain that originated from solidification shrinkage and high-temperature gradient.

- Type B: A large number of type-B LME cracks were formed as a series of cracks in the shoulder of the weld surface; however, they were relatively small cracks with crack lengths ranging from a few micrometers to $100 \mu \mathrm{m}$. High tensile stress was induced at location $B$ as a result of the sudden temperature drop at the edge of the E/S interface and the nonlinear temperature gradient. However, the tensile stress instantly disappeared as the annular region of the electrode came in physical contact with the sheet and exerted high compressive stress. So, the tensile stress and the source of liquid zinc were interrupted during the weld time; hence, the crack propagation ceased at a relatively smaller crack length. The same action continued with increasing electrode indentation to produce numerous type$\mathrm{B}$ cracks in the shoulder region of the weld surface. Moreover, the microstructure consisting of ferrite also opposed crack propagations in location $B$ because the ferritic phase is not favorable for LME cracking.

- Type C: Large LME cracks (up to $1200 \mu \mathrm{m}$ ) were formed at the periphery of the weld surface. The temperature drop at the edge of the E/S interface and the nonlinear temperature gradient due to the mechanical collapse caused the development of tensile stress during weld time at location $C$, which continued to exist till the hold time. It resulted in high values of tensile stress and $\Delta t_{\mathrm{TS}}$. Also, location $C$ never confronted the electrode and, hence, the temperature kept on increasing till the end of the weld time, which resulted in high $\Delta \mathrm{t}_{\mathrm{LZ}}$ along with a fully austenite microstructure. As a result, the liquid zinc had sufficient time to penetrate deep into the steel sheet through the austenite grain boundaries at a higher tensile stress to create large LME cracks.

- Type D: A few short LME cracks (less than $100 \mu \mathrm{m}$ ) occurred at the S/S interface outside the nugget only at higher heat inputs. The tensile stress induced due to the cooling of the solid metal during hold time was responsible for the formation of small, type-D LME cracks, although low in magnitude.

In conclusion, the nature of the contact condition between the electrode as well as the steel sheet and the heat input during welding are the major reasons for the difference in thermal, mechanical, and metallurgical characteristics of these locations during welding, which caused the formation of various types of LME cracks in spot welds.

\section{Acknowledgments}

This work was supported by the Korea Basic Science Institute National Research Facilities \& Equipment Center grant and funded by the Ministry of Education, Korea government (No. 2019R1A6C1010045). The authors thank Dr. Murali Tumuluru (an independent welding consultant and a lecturer who has worked in the steel industry for the past 23 years) for his valuable suggestions and comments, which allowed the authors to greatly improve the quality of the manuscript.

\section{References}

1. Marder, A. R. 2000. Metallurgy of zinc-coated steel. Progress in Materials Science 45: 191-271. DOI: 10.1016/S0079-6425(98) 00006-1

2. Tumuluru, M. 2007. The effect of coatings on the resistance spot welding behavior of $780 \mathrm{MPa}$ dual-phase steel. Welding Journal 86(6): 161-s to 169 -s.

3. Milititsky, M., Pakalnins, E., Chonghua, J., and Thompson, K. A. 2003. On characteristics of DP600 resistance spot welds. SAE Transactions: Journal of Materials and Manufacturing 112: 244-251. DOI: 10.4271/2003-01-0520

4. Beal, C., Kleber, X., Fabregue, D., and Bouzekri, M. 2012. Liquid zinc embrittlement of twinning-induced plasticity steel. Scripta Materialia 66(12): 1030-1033. DOI: 10.1016/j.scriptamat.2011.12. 040

5. Mendala, J. 2012. Liquid metal embrittlement of steel with galvanized coatings. IOP Conference Series: Materials Science and Engineering 35: 012002. DOI: 10.1088/1757-899X/35/1/012002

6. Cho, L., Kang, H., Lee, C., and De Cooman, B. C. 2014. Microstructure of liquid metal embrittlement cracks on $\mathrm{Zn}$-coated 22MnB5 press-hardened steel. Scripta Materialia 90: 25-28. DOI: 10.1016/j.scriptamat.2014.07.008

7. Pouranvari, M., and Marashi, S. P. H. 2013. Critical review of automotive steels spot welding: Process, structure and properties. Science and Technology of Welding and Joining 18(5): 361-403. DOI: 10.1179/1362171813Y.0000000120

8. Seo, J. C., Choi, I. D., Son, H. R., Ji, C., Kim, C., Suh, S. B., Seo, J., and Park, Y. D. 2015. A comparative study of constant current control and adaptive control on electrode life time for resistance spot welding of galvanized steels. Journal of Welding and Joining 33: 47-55. DOI: 10.5781/JWJ.2015.33.2.47

9. Chang, I. S., Cho, Y. J., Park, H. S., and So, D. Y. 2016. Importance of fundamental manufacturing technology in the automotive industry and the state of the art welding and joining technology. Journal of Welding and Joining 34(1): 21-25. DOI: 10.5781/JWJ. 2016.34.1.21

10. Ji, C., Park, C., Kim, C., Cho, Y., Oh, D., Kim, M. H., Kim, Y. D., and Park, Y. D. 2017. A comparative study of weldable current range on $\mathrm{AC}$ and MFDC resistance spot welding for $440 \mathrm{MPa}$ grade steel sheet. Journal of Welding and Joining 35: 34-42. DOI: 10. 5781/JWJ.2017.35.1.34

11. Sigler, D. R. 2008. Observations of liquid metal-assisted cracking in resistance spot welds of zinc-coated advanced highstrength steels. Sheet Met. Weld. Conf. XIII., Livonia, Mich., pp. $1-17$.

12. Gaul, H., Brauser, S., Weber, G., and Rethmeier, M. 2011. Methods to obtain weld discontinuities in spot-welded joints made of advanced high-strength steels. Welding in the World 55: 99-106. DOI: $10.1007 / \mathrm{BF} 03321547$

13. Ashiri, R., Haque, M. A., Ji, C. W., Shamanian, M., Salimijazi, H, R., and Park, Y. D. 2015. Supercritical area and critical nugget diameter for liquid metal embrittlement of Zn-coated twining induced plasticity steels. Scripta Materialia 109(1): 6-10. DOI: 10.1016/j.scriptamat.2015.07.006

14. Tumuluru, M. 2016. Resistance spot welding of new generation of high strength automotive steels. $10^{\text {th }}$ Int. Conf. Trends Weld. Res. and $9^{\text {th }}$ Int. Weld. Symp. Japan Weld. Soc., Tokyo, Japan., p. 584.

15. Tumuluru, M. 2017. Evolution of generation 3 automotive steels and some studies on their weldability behavior. Int. Welding/ Joining Conf., p. 15120. 
16. DiGiovanni, C., Biro, E., and Zhou, N. Y. 2018. Impact of liquid metal embrittlement cracks on resistance spot weld static strength. Science and Technology of Welding and Joining 24(3). DOI: 10.1080/13621718.2018.1518363

17. Ashiri, R., Shamanian, M., Salimijazi, H. R., Haque, M. A., Bae, J. H., Ji, C. W., Chin, K. G., and Park, Y. D. 2016. Liquid metal embrittlement-free welds of $\mathrm{Zn}$-coated twinning induced plasticity steels. Scripta Materialia 114: 41-47. DOI: 10.1016/j.scriptamat. 2015.11.027

18. Choi, D. Y., Sharma, A., Uhm S. H., and Jung, J. P. 2018. Liquid metal embrittlement of resistance spot welded 1180 TRIP steel: Effect of electrode force on cracking behavior. Metals and Materials International 25: 219-228. DOI: 10.1007/s12540-018-0180-x

19. Jung, G., Woo, I. S., Suh, D. W., and Kim, S. J. 2016. Liquid Zn assisted embrittlement of advanced high strength steels with different microstructure. Metals and Materials International 22: 187-195. DOI: 10.1007/s12540-016-5579-7

20. Kang, H., Cho, L., Lee, C., and De Cooman, B. C. 2016. Zn penetration in liquid metal embrittled TWIP steel. Metallurgical and Materials Transactions A 47(6): 2885-2905. DOI: 10.1007/ s11661-016-3475-x

21. Kim, Y. G., Kim, I. J., Kim, J. S., Chung, Y. I., and Choi, D. Y. 2014. Evaluation of surface crack in resistance spot welds of Zncoated steel. Materials Transactions 55(1): 171-175. DOI: 10.2320/ matertrans.M2013244

22. Barthelmie, J., Schram, A., and Wesling, V. 2016. Liquid metal embrittlement in resistance spot welding and hot tensile tests of surface-refined TWIP steels. IOP Conference Series: Materials Science and Engineering 118(1): 012002. DOI: 10.1088/1757899X/118/1/012002

23. Bhattacharya, D. 2018. Liquid metal embrittlement during resistance spot welding of $\mathrm{Zn}$-coated high-strength steels. Materials Science and Technology 34(15): 1-21. DOI: 10.1080/02670836. 2018.1461595

24. Murugan, S. P., Mahmud, K., Ji, C., Jo, I., and Park, Y. D. 2019. Critical design parameters of the electrode for liquid metal embrittlement cracking in resistance spot welding. Welding in the World 63: 1613-1632. DOI: 10.1007/s40194-019-00797-y

25. American Welding Society. 2012. D8.9M:2012, Test Methods for Evaluating the Resistance Spot Welding Behavior of Automotive Sheet Steel. Miami, Fla.: American Welding Society.

26. Li, Y., Wei, Z., Li, Y., Shen, Q., and Lin, Z. Q. 2013. Effects of cone angle of truncated electrode on heat and mass transfer in resistance spot welding. International Journal of Heat and Mass Transfer 65: 400-408. DOI: 10.1016/j.ijheatmasstransfer.2013.06.012

27. Fonstein, N. 2015. Advanced High Strength Sheet Steels. Springer International Publishing. DOI: 10.1007/978-3-31919165-2

28. American Welding Society. 1991. Welding Handbook: Welding Processes, Part 2, $9^{\text {th }}$ ed. Jenney, C. L., and O'Brien, A., eds. Miami, Fla.: American Welding Society.

29. Wolski, K., and Laporte, V. 2008. Grain boundary diffusion and wetting in the analysis of intergranular penetration. Materials Science and Engineering A 495(1-2): 138-146. DOI: 10.1016/J. MSEA.2007.10.107

30. Saha, D. C., Chang, I., and Park, Y. D. 2014. Heat-affected zone liquation crack on resistance spot welded TWIP steels. Materials Characterization 93: 40-51. DOI: 10.1016/j.matchar.2014.03.016

31. Takashima, K., Sawanishi, C., Taniguchi, K., Matsuda, K., and Ikeda, R. 2017. Development of resistance spot welding technology to suppress LME crack in ultra high strength steel sheets. Preprints of National Meeting of JWS. DOI: 10.14920/jwstaikai. 2017s.0_16

32. Zhang, H., and Senkara, J. 2017. Resistance Welding: Fundamentals and Applications, $2^{\text {nd }}$ ed. CRC Press, Taylor \& Francis Group Boca Raton, Fla.

33. Senkara, J., and Zhang, H. 2000. Cracking in spot welding aluminum alloy AA5754. Welding Journal 79(7): 194-s to 201-s.

34. Zhang, H., Senkara, J., and Wu, X. 2002. Suppressing cracking in resistance welding AA5754 by mechanical means. Journal of Manufacturing Science and Engineering 124(1): 79-85. DOI: 10.1115/1.1418693

35. El-Badry, M. M., and Ghali, A. 1983. Nonlinear temperature distribution and its effects on bridges. IABSE Proceedings: 169-191. DOI: 10.5169/seals-37501

36. Wintjes, E., DiGiovanni, C., He, L., Bag, S., Goodwin, F., Biro, E., and Zhou, Y. 2019. Effect of multiple pulse resistance spot welding schedules on liquid metal embrittlement severity. Journal of Manufacturing Science and Engineering 141(10): 1-9. DOI: $10.1115 / 1.4044099$

37. Nied, H. A. 1984. The finite element modeling of the resistance spot welding process. Welding Journal 63(4): 123-s to 132-s.

38. DiGiovanni, C., Bag, S., Mehling, C., Choi, K. W., Macwan, A., Biro, E., and Zhou, Y. 2019. Reduction in liquid metal embrittlement cracking using weld current ramping. Welding in the World 63: 1583-1591. DOI: 10.1007/s40194-019-00790-5

39. Beal, C. 2011. Mechanical behaviour of a new automotive high manganese TWIP steel in the presence of liquid zinc. $\mathrm{PhD}$ thesis, L'Institut National des Sciences Appliquées de Lyon.

40. Razmpoosh, M. H., Macwan, A., Biro, E., Chen, D. L., Peng, Y., Goodwin, F., and Zhou, N. 2018. Liquid metal embrittlement in laser beam welding of $\mathrm{Zn}$-coated 22MnB5 steel. Materials and Design 155: 375-383. DOI: 10.1016/J.MATDES.2018.05.065

41. Kim, D., Kang, J. H., and Kim, S. J. 2018. Heating rate effect on liquid $\mathrm{Zn}$-assisted embrittlement of high $\mathrm{Mn}$ austenitic steel. Surface and Coatings Technology 347: 157-163. DOI: 10.1016/ j.surfcoat.2018.04.081

42. Lippold, J. C. 2015. Welding Metallurgy and Weldability. Hoboken, N.J.: Wiley and Sons. DOI: 10.1002/9781118960332

43. Kou, S. 2002. Welding Metallurgy, $2^{\text {nd }}$ ed. Hoboken, N.J.: Wiley and Sons. DOI: 10.1002/0471434027

SIVA PRASAD MURUGAN and YEONG-DO PARK (ypark@deu.ac. $\mathrm{kr}$ ) are with the Department of Advanced Materials Engineering, Dong-Eui University, Busan, Korea. VIJEESH VIJAYAN is with the Department of Mechanical Engineering, NMAM Institute of Technology Nitte, Karkala Udupi, India. CHANGWOOK $J$ is with the Advanced Forming Process R\&D Group, Korea Institute of Industrial Technology, Ulsan, Korea. 